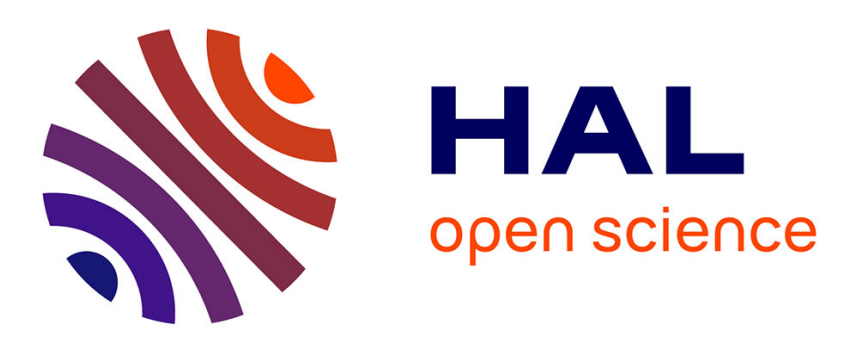

\title{
Seismic Response of a Mountain Ridge Prone to Landsliding
}

Claire Rault, Wei-An A Chao, Céline Gelis, Arnaud Burtin, Jui-Ming M Chang, Odin Marc, Tz-Shin S Lai, Yih-Min M Wu, Niels Hovius, Patrick Meunier

\section{To cite this version:}

Claire Rault, Wei-An A Chao, Céline Gelis, Arnaud Burtin, Jui-Ming M Chang, et al.. Seismic Response of a Mountain Ridge Prone to Landsliding. Bulletin of the Seismological Society of America, 2020, 110 (6), pp.3004-3020. 10.1785/0120190127 . hal-03357373

\section{HAL Id: hal-03357373 https://hal.science/hal-03357373}

Submitted on 15 Oct 2021

HAL is a multi-disciplinary open access archive for the deposit and dissemination of scientific research documents, whether they are published or not. The documents may come from teaching and research institutions in France or abroad, or from public or private research centers.
L'archive ouverte pluridisciplinaire HAL, est destinée au dépôt et à la diffusion de documents scientifiques de niveau recherche, publiés ou non, émanant des établissements d'enseignement et de recherche français ou étrangers, des laboratoires publics ou privés. 


\section{Seismic response of a mountain ridge prone to landsliding}

C. Rault, W.A. Chao, C. Gelis, A. Burtin, J.M. Chang, O. Marc, T.S. Lai, Y.M. Wu, N. Hovius, P. Meunier

Corresponding author: clairerault@gmail.com

\section{Abstract}

During an earthquake, site effects can play an important role in triggering landslides. To document the seismic response of steep hillslopes, we deployed broadband seismometers across a mountain ridge in Taiwan, in an area with a high earthquake-induced landslide hazard. The ridge has a simple, representative shape and landslides have previously occurred there. Our seismometer array has recorded continuously during more than one year, with both ambient-noise and regional moderate earthquakes as sources. Processing horizontal and vertical signal components, we show that the ridge has a complex response, which we attribute to the combined effects of the subsurface geology and the topographic geometry. Amplification and directionality of ground motion are observed both high and lower on the ridge, giving rise to localized elevated earthquake-induced landslide hazard. Our database contains earthquakes with mostly similar locations, making it difficult to determine the effect of earthquake backazimuth on the ridge response. A part of the ridge response, possibly due to topographic effects, seems to be explained by a model derived from a frequency scale curvature proxy at low frequency. If correct, this would be a promising first step towards improving local ground motion estimation in mountain areas. However, the definition of appropriate scaling parameters of site effects based on geophysical measurements, for use in regional and global landslide hazard equations applicable to mountain areas with substantial regolith thickness, remains a significant challenge. 


\section{Introduction}

25 Large, shallow earthquakes frequently cause important concentration of damage close to ridge crests in mountain areas (Celebi 1991; Ponti and Wells 1991; Tibaldi et al.,1995; Assimaki et al., 2005, Meunier et al., 2008, Sepulveda et al., 2005, Pelekis et al., 2017).

Topographic site effects correspond to amplification or reduction of the ground motion due to the interaction of incoming seismic waves with the local surface topography. It is known that topography

30 plays a significant role in the amplitude, the polarization and the duration of ground motion (Assimaki and Jeong, 2013; Kaiser et al., 2013). Often, the concentration of damage high on slopes is seen as a possible indicator of strong shaking resulting from such site effects (Assimaki and Jeong, 2013; Kaiser et al., 2013). Findings from numerical models and observations from temporary seismic networks on ridges have yielded three insights: (i) Ground motion is often higher at a ridge crest than at the base due to

35 focusing of seismic waves (Davis and West, 1973; Ashford and Sitar, 1997; Nguyen and Gatmiri, 2007); (ii) Frequency and amplitude of topographic amplification are determined by the shape and size of the ridge (Boore, 1973; Bard, 1982; Geli et al., 1988; Ashford et al., 1997; Maufroy et al., 2015) and (iii) Directional amplification transverse to the ridge elongation have been regularly observed at crests (Bouchon et al., 1996; Chávez-Garcia et al., 1996; Spudich et al., 1996; Buech et al., 2010; Massa et al., 40 2014; Cultrera et al., 2016; Hailemikael et al., 2016).

Not only the Earth's surface topography influences seismic ground motion. Lithology and local geological structures also do so. Models usually do not reproduce the recorded amplification of ground motion in a topography without accounting for geological site effects, for example, those arising from impedance contrasts between unconsolidated superficial layers and the bedrock underneath (Steidl et al.,

45 1996; Assimaki et al., 2005; Glinsky and Bertrand, 2017; Jeong et al., 2019). Moreover, directional amplification of ground motion at the ridge crest when observed is consistent, in some cases, with the presence of geological structures, fractures, landslides, or other discontinuities, suggesting that those 2 
structures may also have a directional effect on ground motion (Del Gaudio and Wasowski, 2007; Burjánek et al., 2010; Moore et al., 2012; Pischiutta et al., 2018).

50 In addition to site complexities, earthquake azimuths may also influence site response. To simulate farfield incident motion, incoming waves are usually assumed to propagate vertically upward from the bottom of a ridge. However, waves from nearby and shallow earthquakes (distance $<30 \mathrm{~km}$ and depth $<$ $15 \mathrm{~km}$ ), may have an oblique incidence, affecting both the amplitude and the location of maximum strong motion (Kawase and Aki, 1990; Alfaro et al., 2012). Such earthquakes, are often the most damaging.

55 Massa et al., (2010) proposed that sources with a back-azimuth transverse to the ridge elongation generate stronger ground motion on ridges, whereas Hartzell et al., (2014) observed the opposite, with stronger amplification for waves aligned with the ridge elongation. Both concluded that further investigations are needed to assess the effect of earthquake azimuth on ground motion in the presence of topography.

This brief review highlights the complexity of ridge response to earthquakes. Deficient understanding of 60 this complexity limits our ability to extrapolate observations of ground motion in a particular topography to neighboring ridges and to regional scale, and to parameterize and test global models. However, observational and modeling progress are being made.

Small, temporary arrays of around ten seismic sensors have been deployed to study topographic effects at a local scale. Such arrays complement permanent stations of worldwide networks, which commonly lack

65 instruments located on steeper slopes (Figure 1). Ambient-noise and earthquakes recorded by local arrays have been used to characterize topographic effects on seismic response (Pedersen et al., 1994; ChávezGarcia et al., 1996; Del Gaudio et al., 2008; Hough et al., 2010; Burjánek et al., 2014; Massa et al., 2014). Noise analysis has provided relevant information on the dominant frequency and principal directions of vibration of the site response over a short time at a station. Moreover, analysis of earthquake signals can 70 give an estimate of the amplification of ground motion at a site, and its dominant direction. However, assessing ground motion amplification requires the use of a reference site, which is often difficult to find 53 
(Steidl et al., 1996). In recent years, an increasing number of study sites has made it possible to begin relating topographic site effects to site characteristics, like topographic curvature or local shear wave velocity structure (Burjánek et al., 2014; Maufroy et al., 2015; Pischiutta et al., 2018).

75 Prediction of ground motion at ridges, where data are not usually available, has been explored in several studies, often relying on simple topographic models (Paolucci, 2002; Maufroy et al., 2015; Grelle et al., 2016; Rai et al., 2016). Recently, Maufroy et al., (2015) proposed a model to map topographic amplification based on the curvature of topography derived from digital elevation model at a given wavelength. This model predicted larger topographic site effects at ridge locations where damage was observed after the Amatrice earthquake in Italy (Maufroy et al., 2018). Grelle et al., (2018) presented a litho-morphometric model that considers stratigraphic and topographic effects of ridges, allowing a more realistic assessment of the response of a complex topography to seismic excitation.

These advances have not yet systematically informed the analysis of earthquake-triggered landsliding. Numerous studies of earthquake-triggered landsliding have used simple proxies to characterize the

85 shaking, such as Peak Ground Acceleration (PGA), Velocity (PGV) or Arias intensity (Wilson and Keefer, 1985; Sepulveda et al., 2005; Lee et al., 2008; Meunier et al., 2008; Hung et al., 2018). In these studies, proxies are often extracted from Shake Maps (U.S. Geological Survey, 2017). These proxies do not necessarily characterize well the spatial variability of ground motion in mountainous areas, including the site effects, that are known to play an important role in the triggering of landslides (Bourdeau et al., 90 2004). Moreover, they may not reflect the complexity of the site response over the frequency range that is relevant for seismic landslide triggering (Massey et al., 2018). Choosing a proxy that adequately integrates site effects for global landslide models remains a challenge.

In this study, we focus on a simple mountain ridge in East Taiwan, where the landslide hazard is particularly high due to high seismic activity and the frequent occurrence of intense rainfall. The ridge is 95 similar to many in Taiwan's Central Range, both in size and shape (Meunier et al., 2008) and has been 4 
affected by landsliding. It borders the Longitudinal Valley, which hosts the eponymous active fault. Along this fault, peak ground acceleration is thought to exceed $0.6 \mathrm{~g}$ with a 475 -year return period (Cheng et al., 2007). Shaking of this magnitude can trigger thousands of landslides in steep mountain ridges, as happened during the $\mathrm{M}_{\mathrm{w}}$ 7.6 Chi-Chi earthquake in western Taiwan, in 1999 (Liao and Lee, 2000; Marc et al., 2016). Here, we document the seismic response of the studied ridge, and evaluate the reliability of models which use topographic proxies to map ground motion patterns in terrain with thick regolith. To this end, we have instrumented the ridge with broadband seismometers for almost one year, permitting exploration of the ridge response to earthquakes and to noise. We use horizontal to vertical spectral ratio (HVSR) and polarization analysis at each station to identify potential site effects, and characterize the

105 behavior (site-specific frequency and directional effect) along the ridge flanks. We calculate the Standard Spectral Ratio (SSR) to study the site response to earthquakes, quantify amplification relative to a nearby reference site, and identify directional effects along the ridge. With the SSR of earthquakes, we also study the influence of earthquake back-azimuth on the ridge response.

To advance site specific landslide hazard evaluation, we compare the pattern of ground motion 110 amplification observed on the instrumented ridge, with the pattern predicted by the frequency-scaled curvature model (Maufroy et al., 2015). Our study shows the complexity of the seismic response of relief with thick regolith and provides important elements of discussion concerning earthquake triggered landslide hazard on topographic relief.

\section{Monitoring setting and data}

115 From March 2015 to June 2016, a seismic array was deployed across a mountain ridge in Hualien County, east Taiwan. The ridge, shown as A1 in Figure 2, is a promontory of the Taiwan Central Range, abutting the sediment-filled Longitudinal Valley. It is $800 \mathrm{~m}$ tall $3150 \mathrm{~m}$ wide at the base, with an approximately triangular cross section; its longitudinal axis is oriented $\mathrm{N} 87^{\circ}$, with a secondary, perpendicular branch, $\mathrm{A} 2$, oriented $\mathrm{N} 177^{\circ}$. The western part of the ridge is composed of quartz schist and quartzite of the 5 
120 Hutoushan formation. Mica-schists of the Senjung formation underlie the eastern part. Throughout, the geological layering dips about $20^{\circ}$ toward the northeast (Figure 2, MOEA and Central Geological Survey, 2008). The shear wave velocity $\left(V_{s}\right)$ on the ridge is estimated to be about $3000 \mathrm{~m} \cdot \mathrm{s}^{-1}$, as suggested by Kim et al., 2005 and Lin et al., 1998 for this site. This is a common value for schists and mica-schists (Astier, 1971). A mix of in-place and displaced weathering products, soil and coarser covers the ridge slopes,

125 attesting to the occurrence of gravitational movements in the past. The last recorded landslide occurred in the south flank of the ridge during the winter 2013. This landslide may have been triggered by an earthquake as about 20 events with $\mathrm{M}_{\mathrm{L}}>4$ occurred at shallow depths $(<20 \mathrm{~km})$ within $50 \mathrm{~km}$ range that winter according to the Taiwan Central Weather Bureau earthquake catalog. Several older landslide scars are visible in both flanks (Figures 2 and S1 available in the online supplements). Steep mountain rivers 130 bound the ridge on both sides, the Wanliqiao River to the north and the Mataian River to the south, both flowing towards $\mathrm{N} 90^{\circ}$, in $>100 \mathrm{~m}$ wide gravel beds. At the ridge end, they join the Longitudinal Valley, which is filled with Holocene sand and gravel layers.

Seven three-component broadband seismometers were installed: six on the ridge (Trilium compact $120 \mathrm{~s}$ stations 1 to 6 with Cube 3D dataloggers) and one in the longitudinal valley (Güralp CMG-6TD - station

135 7, with a built-in datalogger) (Figure 2). Stations 1 and 5 were located at the base of the southern and northern ridge flanks, respectively. Station 3 was located on the ridge crest, in between Stations 1 and 5, and Station 6 occupied a ridge crest position farther to the east. Stations 2 and 4, in mid-flank positions, completed the array. The latter was located on the crest of the secondary ridge A2. At all stations, data were recorded continuously with a sampling rate of $100 \mathrm{~Hz}$. Additionally, the Taiwan Central Weather

140 Bureau (CWB) provided continuous records from the broadband station EGFH, located in the Longitudinal Valley about $3 \mathrm{~km}$ south of Station 7. Station EGFH was equipped with a borehole seismometer (Güralp CMG 3TB, with $100 \mathrm{~Hz}$ sampling rate) at $163 \mathrm{~m}$ depth in sediment. The shear wave velocity $(V s)$ of the sediment layer above the instrument of Station EGFH is about $850 \mathrm{~m} . \mathrm{s}^{-1}$ (Wang et al., 
2016). Lack of access has precluded geophysical assessment of the velocity profile under the ridge sites.

145 The ensuing limitations are discussed later in this paper.

Our array recorded $>2000$ earthquakes with a local magnitude greater than $\mathrm{M}_{\mathrm{L}}=3$, within a radius of $200 \mathrm{~km}$. Here, we focus at most on 79 of these events with a good signal to noise ratio. Due to the geodynamics of the region, many of the recorded earthquakes were located to the North-East of the study site (about one third), the others were located along a North-South alignment, to the East of the ridge. For an example, figure 3 shows recordings at the different stations of an earthquake with moment magnitude $\mathrm{M}_{\mathrm{w}}$ 5.5, located $111 \mathrm{~km}$ South-East of the ridge. Ground motion velocities were larger at stations 1 and 3, located at the top and southern base of the ridge than at station 5, located at the northern base of the ridge. Borehole station EGFH, which does not have surface effects, recorded the lowest ground motion. Surface ground motion at the top of this station is expected to be about three times greater (Kuo et al., 2018).

\section{Ambient-noise analysis}

Past studies (e.g., Chávez - Garcia et al., 1996) have shown that ambient-noise analysis can reveal some site properties and give estimates of site specific response (Bard, 1998). In order to identify site-specific frequency and directional effects, we computed the Horizontal to Vertical Spectral Ratio (HVSR) (SESAME, Bard et al., 2004) and the Time Frequency Polarization Analysis (TFPA) (Burjánek et al., 2010) for each station of the network. These methods rely on ground motion recordings at a single station.

\section{Estimation of fundamental resonance using HVSR}

A current method for site response characterization uses the HVSR (Nakamura 1989, Bard et al., 2004). The lowest frequency peak in the HVSR is interpreted as the fundamental resonance frequency of a site. The definition of a peak is provided in the SESAME project (Bard et al., 2004). The presence of a peak

may be related to a variety of phenomena including the Rayleigh wave ellipticity and the S-wave resonance (Bonnefoy-Claudet et al., 2006). Although this method was developed for locations with 1D 
site effects, some studies propose that it may also provide interesting results for more complex sites, including slopes with landslides (Chávez-Garcia et al., 1996; Del Gaudio et al., 2018).

The HVSR is defined as a function of frequency $f$ as:

$170 \quad \operatorname{HVSR}(f)=\frac{\sqrt{S_{N}(f)^{2}+S_{E}(f)^{2}}}{\sqrt{2} S_{Z}(f)}$

Where $S_{j}(f)$ is the amplitude Fourier spectrum of the North $(j=\mathrm{N})$, East $(j=\mathrm{E})$ and Vertical $(j=\mathrm{Z})$ components at frequency $f$.

We calculated and interpreted the HVSR following the SESAME guidelines (Bard et al., 2004). To calculate the vertical and horizontal Fourier amplitude spectra at a given site, we first extracted about 100 windows of ambient noise, lasting for $25 \mathrm{~s}$ each, synchronously for each component. All windows were selected during dry nights (1 a.m. - 3 a.m. local time) to reduce meteorological and anthropogenic signals, such as rainfall and road traffic. Subsequently, the Fast Fourier Transform (FFT) was calculated on each component after applying a cosine tapering of $5 \%$ on the time signal. We smoothed the amplitude Fourier spectrum using a Konno-Omachi filter (Konno and Ohmachi, 1998) setting the smoothing coefficient $b=40$. For each time window, the HVSR was calculated following equation 1 . Finally, we calculated the mean and standard deviation of the HVSR as a function of frequency.

Before interpretation of an HVSR curve, we checked the validity of the following three reliability conditions, as defined in the SESAME guidelines (Bard et al., 2004):

1. The fundamental frequency $f_{0}$ is greater than 10 times the inverse of the window length $l_{w}$ of the signal portion selected. Therefore, the first investigated frequency here is $0.4 \mathrm{~Hz}$.

2. The number of significant cycles $n_{c}$ is greater than 200. $n_{c}$ is equal to $l_{w} . n_{w} . f_{0}$, with $n_{w}$ the number of windows of length $l_{w}$ selected for calculation of the average and standard deviation of the HVSR. 
3. The standard deviation is lower than 2 (resp. 3) for frequencies between $\left[0.5 f_{0} ; 2 f_{0}\right]$, if $f_{0}$ is greater than $0.5 \mathrm{~Hz}$ (resp. $f_{0}$ lower than $0.5 \mathrm{~Hz}$ ).

We focused our analysis on the 1 to $10 \mathrm{~Hz}$ frequency band, as ground motion in this frequency band has been considered by several authors to be the most likely to be responsible for landslide triggering (e.g., Spudich and Frazer, 1984, Jibson et al., 2004). Slope destabilization is frequency dependent, and the optimum frequency for failure is the one that maximizes the shearing. For example, weak surficial materials are most sensitive to high frequencies (Wartman et al., 2005; Bozzano et al., 2008).

Figure 4 shows the mean of the HVSR (plus or minus one standard deviation) as a function of frequency for each station of the array. Stations 1 and 7 presented sharp peaks of amplitude at $3 \mathrm{~Hz}$ and $0.8 \mathrm{~Hz}$, respectively. Stations 2, 4, 5, and 6 showed broad peaks around $5 \mathrm{~Hz}, 4 \mathrm{~Hz}, 5.5 \mathrm{~Hz}$ and $6 \mathrm{~Hz}$, respectively. Station 3 had an almost flat HVSR over a wide frequency band, composed of multiple peaks between $1 \mathrm{~Hz}$ and $4 \mathrm{~Hz}$, with similar HVSR amplitude around 3. Station EGFH had an almost flat response with HVSR amplitude lower than 2.

Following the SESAME guidelines (Bard et al., 2004), we only propose interpretations for stations 1 and 7, which have clear peaks (see Bard et al., 2004 for more details). Such peaks, sharp and stable in amplitude and frequency, can be attributed to a resonance at corresponding frequency $f_{0}$ and related to 1D lithological site effects due to the presence of a sedimentary layer overlying a harder bedrock, at a station. For other stations, we will speak in the following about "site-specific" frequencies.

The resonance frequency $f_{0}$ of a $1 \mathrm{D}$ sedimentary layer is expressed as $f_{o}=V_{s} / 4 \mathrm{H}$, with $V_{s}$ the mean shear wave velocity in the sedimentary layer and $H$ the thickness of the layer (Kramer, 1996). We assume that $V_{s}$ is about $600 \mathrm{~m} \cdot \mathrm{s}^{-1}$ at station 1 , consistent with the $V_{s} 30$ value at station HWA020 of the CWB network, $21014 \mathrm{~km}$ farther North in a valley similar to the Mataian Valley in which Station 1 is located (Central Weather Bureau, 2018). Under this assumption, the $3 \mathrm{~Hz}$ peak at Station 1 can be the expression of the 
resonance of a $50 \mathrm{~m}$ thick sedimentary fill in the Mataian Valley. If this assumption also holds at Station 7, then its $0.8 \mathrm{~Hz}$ HVSR peak corresponds to a deeper sediment fill of about $185 \mathrm{~m}$. These fill depths are geomorphologically realistic, and they correspond to a lower bound because we assume that $V_{s}$ is equal to

$215 V_{s} 30$ throughout the sedimentary layer. To improve on these estimates, complementary geophysical investigations would be needed.

\section{Site polarization assessment using time-frequency polarization analysis}

Site properties can influence the polarization of the particle motion (i.e. its shape and orientation). A site is polarized when the particle motion is elliptical. Polarized sites, with a preferential direction of motion,

220 have previously been found, amongst others, at ridge crests and on landslide-prone slopes (e.g., Del Gaudio et al., 2008, Burjánek et al., 2014). We have evaluated the polarization at the study sites using the time-frequency polarization analysis (TFPA) introduced by Burjánek et al., (2010). Using continuous recording stations, this method decomposes the coherency matrix using principal component analysis, adopting a continuous wavelet transform. Assuming the particle motion is approximated with an ellipse,

225 the TFPA provides the frequency of occurrence of three polarization parameters: the azimuth and dip of the long axis of the ellipse, and the ellipticity of the particle motion for a given frequency band. The ellipticity is defined as the length ratio of the principal axes of the particle motion ellipsoid. This parameter ranges from one for circular movement in non-polarized ground motion, to zero for linear movement in fully polarized ground motion. Polarized movement at a given frequency $f$ can be

230 directional, with a predominant strike and dip, or non-directional. In TFPA, the time window duration is adapted to the frequency band under consideration, with longer window durations for lower frequencies.

We implemented the TFPA algorithm on data from nine independent dry days, spread over the year, and for each day processed two hours of ambient-noise signals recorded during the night. The TFPA was run on 100 frequency bands between $0.5 \mathrm{~Hz}$ and $15 \mathrm{~Hz}$. We set the parameter of the Morlet's wavelet $\left(\Omega_{0}\right)$

235 that controls time-frequency resolution to $\Omega_{0}=12$. The dip and the azimuth were calculated in 5-degree 10 
intervals and the ellipticity in 0.02 bins. The frequency of occurrence of the three-polarization parameters was then calculated for each frequency band.

Figure 5 shows the polar diagrams of the strike distribution of the particle motion as a function of the frequency calculated on the 18 hours of noise processed. Distributions of ellipticity and dip angle are plotted against frequency in Figure S4. All stations displaying resonance or site-specific frequencies identified with the HVSR approach were polarized, with lower ellipticity drops for these frequencies. This correspondence with HVSR peaks underlines the greater amplitude of the horizontal component of the signal compared to the vertical component at these frequencies, which is confirmed with the distribution of dips (Figure S4). In the following, we therefore consider directional effects to correspond to a preferential azimuth of the motion, expressed in a dominant strike at a given frequency.

Stations 7, 5 and EGFH were not polarized below $10 \mathrm{~Hz}$ (Figure S4), but the others presented directional effects. For example, Station 1 exhibited a drop of ellipticity at $3 \mathrm{~Hz}$ (Figure S4), consistent with a fundamental frequency of $3 \mathrm{~Hz}$, but had only a weak directional site effect, with slightly more frequent NE-SW strikes (Figure 5). This means that the site response at $3 \mathrm{~Hz}$ was independent of the source

250 location. In contrast, Station 3, at the crest of ridge A1, was polarized at multiple frequency peaks between $1 \mathrm{~Hz}$ and $4 \mathrm{~Hz}$ (Figure S4), and exhibited a strong directivity towards N150 in this frequency band (Figure 5). This direction is perpendicular to the strike of the ridge. Similarly, at Station 4, particle motion around $4 \mathrm{~Hz}$ concentrated in the direction $\mathrm{N} 90^{\circ}$, perpendicular to ridge $\mathrm{A} 2$, on which the station was installed. This frequency corresponds to a peak in the HVSR (Figure 4) and to a drop in the ellipticity

255 (Figure S4). At Station 6, particle motion around $6 \mathrm{~Hz}$ was weakly oriented towards $\mathrm{N} 150^{\circ}$, with a corresponding slight drop of the ellipticity, interpreted also as a directional effect.

In summary, we found that noise recordings indicate site-specific features that depend on the station location: 
1. In the borehole station there was no evidence of site effect.

2. At the base of the ridge and in the adjacent valleys, site effects were due to the presence of a sedimentary layer.

3. At ridge crests, directional site effects were observed at the site-specific frequencies.

4. At the crest of ridge A1, horizontal movement was amplified over a large frequency band.

5. In the ridge flanks, and away from crests, no directional effects were found, and site-specific frequencies were observed between $4.5 \mathrm{~Hz}$ to $7 \mathrm{~Hz}$, depending on the site considered.

Farther reaching interpretations of the observed phenomena require better characterization of the local subsurface properties using geophysical measurements.

\section{Earthquake response analysis}

The site-specific features described above were obtained using ambient noise data only. They allowed

270 identification of resonance or site-specific frequencies together with polarization and directional effects. However, such features do not permit quantification of the seismic response of the hill, i.e., the level of ground motion amplification due to site characteristics. During earthquakes, slope stability depends on the intensity of the ground motion, its duration and frequency content (e.g., Jibson et al., 2000, Roy et al., 2015). In the following, we present the amplitude and duration of the ground motion observed across the

275 ridge during a number of earthquakes. From this, we determine the amplification of ground motion and the dominant direction of vibration, if any, at each station, relative to a reference site, and the influence of the earthquake back-azimuth on the seismic response of the sites. The observed amplification pattern is compared to the one derived from frequency scale curvature (FSC) model (Maufroy et al., 2015). In the light of this findings, we examine landslide hazard along the ridge. 
After correction for instrument response, earthquake signals were extracted using a five-step process at each station (see Figure S5). 1) Theoretical arrival times of the P and S waves are calculated using the CWB earthquake catalog, and the velocity model from Chi et al., (2001) up to $85.3 \mathrm{~km}$ depth and IASP 1991 (Kennett and Engdahl, 1991) from $85.3 \mathrm{~km}$ to $6371 \mathrm{~km}$ depth. 2) The signal is selected over a wider time window centered on the earthquake arrival (300 to 560 seconds). 3) The signal is corrected for the mean and linear trend in the window 4) P- and S- time wave arrivals are picked automatically, using the Baillard et al., (2014) algorithm. This algorithm extracts precisely the time at which the signal kurtosis within a sliding window of five seconds is maximal, corresponding to phase onset. 5) Picked P and S phases are verified and manually correct if needed.

290 We have calculated the signal to noise ratio (SNR) as the ratio of the S-wave Fourier amplitude spectrum (Ss) over the noise-wave Fourier amplitude spectrum $(\mathrm{Sn})$. The S-wave and noise windows were selected using the algorithm of Perron et al., (2018). In this algorithm, the S phase window starts at the S wave arrival, and its duration is set as a function of the time between the $\mathrm{S}$ and $\mathrm{P}$ wave arrivals, the magnitude and the distance of the earthquake. We selected three noise windows: one pre-event and two post-event 295 windows that have the duration of the S-phase window, with a minimum of 10s. Further, we chose the noise window with the lowest energy in the frequency band of 1-10 Hz. Only signals with a SNR greater than 3 over the entire frequency band between 1 and $10 \mathrm{~Hz}$ were considered. This is consistent with the study of Perron (2017), which shows that results obtained from a selection of earthquakes with SNR above this threshold are significantly more stable than ones obtained with lower SNR. For the Standard

300 Spectral Ratio calculation (see section Amplification of ground motion and potential dominant direction, below), we only considered distant events, with a source at least $30 \mathrm{~km}$ from the array. This is equivalent to 10 times the distance between the reference station and the array, which is often considered as a threshold for common input ground motion at reference and studied stations (Perron, 2017). 
Figure 6 shows the azimuth distribution, magnitudes $\left(\mathrm{M}_{\mathrm{L}}\right)$, focal depths and hypocental distances of 41 earthquakes with $\mathrm{SNR}>3$ that registered at all six stations on the ridge and EGFH (41 earthquakes, $\mathrm{SNR}>3$ ), and a further 79 earthquakes with $\mathrm{SNR}>3$ that registered only at Stations 3 and EGFH (79 earthquakes, SNR $>3$ and distance $>30 \mathrm{~km}$ ). Figure S6 details the number and the characteristics of earthquakes selected at the other stations.

\section{Peak value and duration of the ground motion along the ridge}

310 The amplitude and the duration of ground motion are parameters that influence slope stability. The ground motion velocity is characteristic of surface deformations induced by the seismic wave (Hill et al., 1993). The associated acceleration characterizes the inertial strength acting on the slope during the shaking. Longer duration of the ground motion means that a slope may undergo a larger number of wave cycles with acceleration and peak velocity causing deformation, thus increasing the probability of slope

315 failure (Jibson et al., 2000; Bozzano et al., 2008).

We extracted the peak ground velocity (PGV), the peak ground acceleration (PGA), the Arias intensity and the significant relative duration of shaking for the 41 selected earthquakes that were well recorded at all six stations. These parameters are often used in landslides hazard studies (e.g., Jibson et al., 2000, 2004, Gallen et al., 2015, Marc et al., 2016, Specht et al., 2019). The Arias intensity $\left(I_{A}\right)$ is defined as

$320 \quad I_{A}=\frac{\pi}{2 g} \int_{0}^{T} a\left(t^{2}\right) d t$, with $T$ the signal duration, $g$ the gravitational acceleration on Earth and $a$ the acceleration of the ground motion. $I_{A}$ has been found to be a reliable parameter to describe the ground motion that triggers landslides (Harp and Wilson, 1995). We also extracted from the signals the significant relative duration (SRD), to quantify the duration of the strong ground motion. It corresponds to the time window containing $90 \%$ of the signal energy, and excluding the first and last $5 \%$ (Trifunac and 325 Brady, 1975). 
Figure 7 shows the box plots of these parameters normalized by the average of the values recorded at all the ridge stations. We notice that there was not a strong spatial disparity of these parameters along the ridge. Studied events had similar time duration at all sites. The PGA was higher at Station 1 and lower at Station 2. The $75^{\text {th }}$ percentile of normalized PGA was equal to about 1.75 at Station 1 . This means that

330 for this station, the ground motion of $25 \%$ of the recorded events had a PGA at least 1.75 times higher than the average PGA of all common recorded events. The Arias intensity was in average 2 times higher at Stations 1 and 0.5 times lower at Station 2 . The $75^{\text {th }}$ percentile of normalized $\mathrm{I}_{\mathrm{A}}$ was about 1.25 at stations 5, 4 and 3. PGV was highest at Stations 3 and 1, with $25 \%$ of the recorded values at least 1.7 times higher than at other stations.

335 If we consider that landslide hazard relates to extreme ground motion, here characterized by the $75^{\text {th }}$ percentile of ground motion parameters, then hazard levels were lowest at Station 2. If it relates to PGA, or $I_{A}$ then landsliding was the most likely to occur at ridge toe and with the same probability at other instrumented positions on the ridge except Station 2. However, if landslide hazard is primarily set by $\mathrm{PGV}$, then it was greatest near the crest and base of the main ridge. This would be in agreement with the

340 location of the landslide which occurred in winter 2013 possibly as a result of an earthquake (Figure S1).

We conclude that, at the ridge scale it is difficult to propose a map of the landslide susceptibility based on these parameters. The small number of events used calls into question the representativity of the observations. A larger number of events may be required for a robust statistical evaluation of the variations of these parameters over the topography, and to draw more meaningful conclusions about 345 landslide hazard on this ridge.

\section{Amplification of ground motion and potential dominant direction}

The standard spectral ratio (SSR, Borcherdt, 1970) is widely used to estimate ground motion amplification at a given frequency, relative to a reference station (Cadet et al., 2011; Massa et al., 2014; Perron, 2017). 
The Standard Spectrum Ratio $\left(S S R_{i, c, e}\right)$ at a station $i$ on the component $c$ for an earthquake $e$ is calculated 350 as follows:

$S S R_{i, c, e}=\frac{S_{i, c, e}}{S_{r, c, e}}$

where $S_{i, c, e}$ is the Fourier amplitude spectrum of station $i$, and $S_{r c e}$ is the Fourier amplitude spectrum of the reference station.

We computed the Fourier amplitude spectrum of each component of the recorded signal between the Parrival minus $1 \mathrm{~s}$ and coda arrival, after applying a 5\% cosine taper. Then, we smoothed the spectrum using Konno-Omachi with a bandwidth coefficient $b$ equal to 40 (Konno and Ohmachi, 1998). The individual spectra are presented in Figure S7.

An optimal reference station is without site effects, located at the surface, and at sufficient distance to remain unaffected by the vibration of the studied topography (Borcherdt, 1970; Sánchez-Sesma and 360 Campillo, 1993; Steidl et al., 1996). A station that meets all these criteria is not available, but Station EGFH is a practicable reference since it does not amplify any particular frequency nor show any directional effects (see previous section). However, this station is located at $163 \mathrm{~m}$ depth in a borehole that does not reach the substratum. This brings limitations, notably the absence of free-surface effects (Cadet et al., 2011), and the possibility of interference between upgoing and downgoing waves (Shearer and Orcutt, 1987; Hollender et al., 2018), which may influence the estimation of site effects. Therefore, calculated SSRs represent site amplification relative to Station EGFH, and not an estimation of the surface-to-surface site effect.

To verify whether or not the directional site-effects suspected with the ambient-noise analysis were preserved during earthquakes, we rotated the horizontal components in 10-degree steps for each studied 

done in the $1-10 \mathrm{~Hz}$ frequency band.

Figure 8 displays the mean (+/- one standard deviation) of the SSR for the north component of each station as a function of frequency. Polar plots show the SSR of the rotated horizontal components. The SSR on the east, vertical and horizontal components of our stations are shown in figures S8, S9 and S10 respectively, in the electronic supplement to this article. At all stations, the maximum amplification on horizontal components relative to Station EGFH was observed around the site-specific frequency identified with the HVSR. At Station 1, we observed SSRs with high amplitude for frequencies above $3.5 \mathrm{~Hz}$ on the horizontal and vertical components. At these frequencies the recorded signals were more than ten times higher than EGFH ones. Above $5 \mathrm{~Hz}$, the amplitude was greater in the direction normal to the Mataian River valley. Station 2 had a 14 times amplification with respect to the borehole signal between $4 \mathrm{~Hz}$ and $7 \mathrm{~Hz}$ on the northern component, without a particular directivity. At Station 3, the northern component was, on average, ten times higher than the EGFH signal, between 1 and $2 \mathrm{~Hz}$. Amplifications at this station were at least 1.2 times higher in the direction perpendicular to ridge A1. At Station 4, amplification was maximum transverse to ridge A2, up to 12 times compared to Station EGFH $385(\simeq 1.5$ times that measured on the northern component), between $3.5 \mathrm{~Hz}$ and $6 \mathrm{~Hz}$. Station 6 showed directional effects transverse to ridge A1 around its site-specific frequency $(6 \mathrm{~Hz})$, with maximum of amplification above 10 times relative to the reference station.

This first part of earthquake observation analysis confirms the site effects identified with noise-analysis at ridge stations. This suggests, as in previous studies (e.g., Panzera et al., 2012; Hartzell et al., 2014), that studying the seismic response of a topographic feature using noise data can inform the prediction its seismic response to at least moderate size earthquakes. We also verified, in this way, that the site-specific frequencies and directionality effects are due to internal specificities of the sites. Considering the ridge structure and its lithological heterogeneities, we suppose that the diversity of the seismic responses 17 
observed along the ridge reflect the influence on ground motion of both topography and geology of the 395 sites (Massa et al., 2014; Hailemikael et al., 2016; Massey et al., 2017).

In addition, we noticed on the vertical SSRs, two peaks of amplification, at around $7 \mathrm{~Hz}$ and $10 \mathrm{~Hz}$, at all ridge stations (Figure S7). The level of amplification at these frequencies was similar for all stations. Most likely, these apparent amplifications were a consequence of the drop in amplitude of the vertical spectrum at the EGFH station at these frequencies. Interference between upgoing and downgoing waves 400 could explain this drop (Cadet et al., 2011). At lower frequencies, only stations located at the crest and base of a ridge showed clear vertical amplification. At Station 3, vertical motion was amplified around $2 \mathrm{~Hz}$ over a fairly wide frequency band. Station 4 showed a similar behavior, although less strong, while Stations 5, 6, 2 and 1 had only minor amplification in this frequency range. At Station 1, located at the base of the ridge, the vertical ground motion was amplified around $5 \mathrm{~Hz}$. This amplification was also 405 visible, but less marked, at Stations 2 and 5.

Taking into account, the analysis on horizontal and vertical SSRs, we first hypothesize that the observed directionality at Station 1 around $6 \mathrm{HZ}$ and its vertical amplification at $5 \mathrm{~Hz}$ may be due to surface waves generated at the edge of the sedimentary fill of the Mataian Valley. These waves could propagate into the adjacent ridge flank (cf. Hallier et al., 2008; Pilz et al., 2018), increasing the duration of ground motion at 410 the base of the ridge (Semblat et al., 2003; Pelekis et al., 2017), and therefore the landslide hazard along the slope. However, we have not clearly identified longer signals at Station 1 compared to other stations (Figure 7), and further analysis of surface waves is required to test this hypothesis. Secondly, we assume that amplification in the broad frequency band around $2 \mathrm{~Hz}$, which was prominent in all components of ridge top Station 3, and affected the vertical component of other ridge stations, may reflect topographic

415 site effects. This is not consistent with the Rayleigh estimate of the 2-D fundamental vibration frequency $f_{0}$ of the ridge given by Paolucci (2002), for a shear wave velocity of about $3000 \mathrm{~m} . \mathrm{s}^{-1}$ (Kim et al., 2005; Huang et al., 2017) and the mountain width $\mathrm{L}=3150 \mathrm{~m}$. This approach yields values of $f_{0}$ in the range of 
0.66-0.93 Hz. However, the mismatch is not surprising, given the 3-D geometry and complex geology of the site (cf. Glinsky and Bertrand, 2017).

420 Therefore to sum up, from here and in the light of previous studies, the best options we have to explain the observed frequencies of amplification and the measured directionality at stations on the studied ridge are (i) the topographic surface geometry; (ii) the stratigraphy; and (iii) subsurface anisotropy due to, for example, landslides, schistosity and/or fractures associated with topographic stress (Del Gaudio et al., 2008; Formisano et al., 2012; Pischiutta and Rovelli, 2014; Hailemikael et al., 2016; Hartzell et al., 2017;

425 Stolte et al., 2017; Assimaki and Mohammadi, 2018). These possible explanations should be tested with detailed numerical models.

In conclusion, observations from noise analysis and earthquakes reveal significant site-effects on the ridge and possible surface-wave generation, that may favor a high propensity to landsliding due to strong ground motion, amplified perpendicular to the ridge elongation at its crests and at its base transverse to valley edges, i.e. in both locations in the direction of steepest slopes.

\section{Influence of earthquake back-azimuth on ridge response}

Several studies suggest that the amplification pattern across mountain ridges changes as a function of the incidence angle and back-azimuth of incoming seismic waves. Below, we test the influence of the earthquake back-azimuth on the site response, following Perron's (2017) study of the seismic response of 435 a sedimentary basin.

We binned 34 earthquakes according to their azimuths in 30-degree intervals (the 41 selected events with $\mathrm{SNR}>3$, minus seven with locations within $30 \mathrm{~km}$ of the ridge), and focused on four subsets with more than 5 events. Identified by their azimuth-center $j$ and number of events $N_{j}$ they are: $\mathrm{N}_{15}=9, \mathrm{~N}_{45}=14, \mathrm{~N}_{75}=5$ and $\mathrm{N}_{135}=5$. We note that these subsets are small, and that their distribution is uneven. For each set we 440 computed the mean SSR: $\overline{S S R}$. 
The distribution of the 34 earthquake-azimuths being not homogeneous (Figures 6 and S6), the mean $\overline{S S R}$ of the 34 earthquakes is biased. Therefore, to quantify whether or not the $\overline{S S R}$ differs from each other because of statistical fluctuation rather than for physical reasons, we first built an unbiased reference $S S R$, and then introduced a confidence interval.

445 To build the reference SSR, we extracted 1000 times the SSR of $K=10$ random events from the pool of 34 recorded events. This yielded a log-normal distribution of SSR at a given frequency (Figure S11). We used a modified Cox method (Olsson, 2005) to compute the confidence interval for this distribution. We defined a log-transformed, normally distributed variable $\mathrm{Y}=\ln \left(S S R\right.$ with a mean $\mu$ and variance $\sigma^{2}$, and for each draw $i$, we obtained the $\log$ of SSR of the $K$ events and calculated the mean $\left(\theta_{i}\right)$ and standard deviation $\left(\gamma_{i}\right)$ at each frequency. Subsequently, the final unbiased mean $(\theta)$ and standard deviation $(\sigma)$ were estimated from these 1000 random draws as:

$\mu=\frac{1}{1000} \sum_{i=1}^{1000} \Theta i$

$\sigma^{2}=\frac{1}{999} \sum_{i=1}^{1000} \gamma_{i}^{2}$

With these parameters, the $p \%$ confidence interval $I C_{p}$ was calculated as

$455 \quad I C_{p}=\left[\mu+\frac{\sigma^{2}}{2}-k_{p} \sqrt{\frac{\sigma^{2}}{N}+\frac{\sigma^{4}}{2(N-1)}} ; \mu+\frac{\sigma^{2}}{2}+k_{p} \sqrt{\frac{\sigma^{2}}{N}+\frac{\sigma^{4}}{2(N-1)}}\right]$.

$k p$ is defined using a percent point function of the Student law with $\mathrm{N}$ degrees of freedom for the probability $p$. Then, the confidence interval of $\overline{S S R}$ was obtained taking the exponential of $I C_{p}$. Having calculated the confidence interval with $\mathrm{p}=95 \%$, one can assess an influence of the earthquake-azimuth on 460 the ridge response with $95 \%$ confidence only if the $\overline{S S R_{j}}$ do not belongs to $I C_{95}$. 20 
Figure 9 shows the mean SSR ( $\overline{S S R}$ ) of events binned by azimuth calculated along the North component. $S S R_{j}$ are colored in gray when the values are within the confidence interval, meaning that the earthquakes with a given azimuth interval $j$ did not result in a significantly higher or lower amplification of the ground motion than the average ground motion. In contrast, for colored curves there is a $95 \%$ 465 chance that earthquakes with this azimuth caused a significantly higher/lower amplification. At all ridge stations except Station 5, the most energetic sources at frequencies between $1.2 \mathrm{~Hz}$ and $6 \mathrm{~Hz}$ were located the North-East (NE) $(j=45$ and $j=15)$. Meanwhile, at Stations 3, 4 and 6, the signals of earthquakes located to the East South East $(j=135)$ (ESE) had significantly lower spectral amplitudes (x 2/3) than the average of all stations, at frequencies between $1 \mathrm{~Hz}$ and $10 \mathrm{~Hz}$.

470 Seismic waves from earthquakes located to the ESE approach the ridge almost parallel to its crest A1. In contrast waves from events located to the NE arrive approximately normal to the ridge crest. Hence, our observations are in line with the results of Massa et al, (2010). However, they should be regarded with caution, because the number of events per bin is really low, compromising the robustness of the statistical analysis. Moreover, we note that, as the studied earthquakes had moderate magnitudes and relatively 475 distant locations, any polarization of the incident waves may not have been related to the source backazimuth. We focused further on four earthquakes. Two had a back-azimuth direction perpendicular to the alignment of Stations 3 and EGFH (i.e. a similar source-to-sites distance), with similar amplification. Waves from these events should reach, in theory, both stations around the same time. The other two were aligned along the lineament of these stations, one to the north-west and the other to the south-east (Figure 480 S12). Waves from the south, arriving parallel to the alignment of Station 3-EGFH, reached EGFH, show the lowest SSR. While the event from the north, reaches first the Station 3 and has similar amplification than those coming in direction perpendicular to the alignment of the two stations. This suggests that the effects observed in figure 9 could be explained by wave attenuation effects between stations, possibly due 
the distance and/or 3D-effects of the Longitudinal Valley basin in which EGFH is set (Maufroy et al., 2016).

\section{Comparison of our observations with a topographic amplification model based on frequency scale curvature}

Recent studies have highlighted the use topographic proxies to estimate the ground motion along topographic relief (e.g., Maufroy et al., 2015; Rai et al., 2016). Maufroy et al., (2015) proposed to 490 estimate the ground motion amplification in mountain area using a frequency-scale curvature proxy (FSC). This method has subsequently been shown suited for mapping of the spatial variation of ground motion along topography in Europe (Maufroy et al., 2018).

We have tested this method on our study site. The main equation of the FSC proxy is:

$$
M A F(f)=8 \cdot 10^{-4} \cdot \frac{V_{s}}{f}+C S\left(L_{s}\right)+1
$$

495 This equation gives the median amplification factor (MAF), at a given frequency $f$ of an S-wave traveling at a velocity $V_{s}$ as a function of a smoothed curvature (CS) over a length $L_{s}=V_{s} / 2 f$. CS is calculated by convolving the curvature of the topography with a normalized smoothing kernel of a characteristic length $L_{s}$. We calculated the curvature using the spatial analysis module of ArcGIS and $30 \mathrm{~m}$ digital elevation model (AW3D30) provided by JAXA. The minimal wavelength $\lambda_{s}$ should not be lower than four times

500 the size of the kernel used for the curvature calculation (Maufroy et al., 2015). Therefore, $\lambda_{\operatorname{Smin}}$ was $360 \mathrm{~m}$ in our case.

We tested the model for three S-wave velocities, $\mathrm{V}_{\mathrm{s}}=3000 \mathrm{~m} \cdot \mathrm{s}^{-1}$, corresponding to the established velocity of the ridge (Lin et al., 1998; Kim et al., 2005), and two lower velocities, $\mathrm{V}_{\mathrm{s}}=1500 \mathrm{~m} \cdot \mathrm{s}^{-1}$ and $\mathrm{V}_{\mathrm{s}}=750 \mathrm{~m} \cdot \mathrm{s}^{-1}$, that may be representative of more weathered or fractured rocks. The maximum resolved 
505 frequency is $f_{\max V s}=\frac{V s}{\lambda s_{\min }}$, which corresponds to $\mathrm{f}_{\max 3000}=8.33 \mathrm{~Hz}, \mathrm{f}_{\max 1500}=4.16 \mathrm{~Hz}$ and $\mathrm{f}_{\max 750}=2.08 \mathrm{~Hz}$. Note that for the lowest velocity the maximum frequency $\left(f_{\max 750}\right)$ that can be computed is low. A very high-resolution topographic model would be required to use the FCS tools for computing the topographic response at higher frequencies.

Figure 10 shows the median topographic amplification estimated using the frequency scale curvature 510 proxy (FSC) and the median amplification calculated on the horizontal component from the 34 selected earthquakes that were recorded at all stations $(\mathrm{SNR}>3$ and distance $\geq 30 \mathrm{~km})$. Note that these amplification levels are not comparable: median SSR entails the amplification due to site effects (topography and geology) and the effect of the free surface, whereas the amplification computed from FSC should only entail effects due to the topography. Regardless of the tested $\mathrm{V}_{\mathrm{s}}$ and frequency, the 515 highest MAF values were obtained at ridge crest sites (Stations 4, 3 and 6), and the lowest at the ridge base (Stations 1 and 2).

For models with $\mathrm{V}_{\mathrm{s}}=3000 \mathrm{~m} \cdot \mathrm{s}^{-1}$, the FSC proxy yielded a higher median amplification factor for Station 3 than all other stations at low frequency. At this station, the predicted ground motion amplification was up to 1.4 times higher than at Station 1 at $3 \mathrm{~Hz}$, and up to 1.8 times higher than at Station 2 at $5 \mathrm{~Hz}$. 520 According to the FSC proxy, the MAF was about 1 at Stations 4, 5 and 6 above $3 \mathrm{~Hz}$, implying no amplification of the ground motion. At Stations 1 and 2, the ground motion was predicted to be attenuated.

For models with $V_{\mathrm{s}}=1500 \mathrm{~m} \cdot \mathrm{s}^{-1}$, the predicted ground motion was amplified at Station 3 and attenuated at Station 1 and 2 below $4 \mathrm{~Hz}$. Similarly, for $\mathrm{V}_{\mathrm{s}}=750 \mathrm{~m} \cdot \mathrm{s}^{-1}$, the maximum MAF was obtained at Station 3, at $5252 \mathrm{~Hz}$, and the predicted MAF was below one at Station 1 and 2 at low frequency.

We recall that for the 34 selected earthquakes, the observed median amplification was high at ridge crest Stations 3 and 6 but also at ridge base Stations 1 and 2. For frequencies below $2 \mathrm{~Hz}$, Station 3 had the 
highest median amplification, up to 2 times more than other stations, which had similar median SSR. At $3 \mathrm{~Hz}$, Station 1 had a median amplification 6 times higher than Stations 2, 5, and 6 and 2 times higher than Station 3. The maximum median amplifications were observed at Stations 1, 4, 2 and 5 at about $3 \mathrm{~Hz}, 4 \mathrm{~Hz}, 6 \mathrm{~Hz}$ and $9 \mathrm{~Hz}$ respectively corresponding to their site-specific frequencies.

Hence, the observed pattern of ground motion amplification across the ridge differs from that obtained with the FSC proxy, despite the fact that this method was proven to be efficient at predicting the groundmotion pattern during the Amatrice earthquake (2016, $\mathrm{M}_{\mathrm{w}} 6.0$, Italy) (Maufroy et al., 2018). One explanation for this disparity may be the geology of the sites. In the Amatrice area, the topographic ridges are made of sandstone, whereas the ridge we have studied is composed of schist and covered by unconsolidated materials (soil and old landslide deposits) that significantly affect the ground motion amplification (see previous sections). Another possible explanation is the difference in resolution of the DEM used for estimation of the roughness of the topography from which the FSC proxy is calculated.

540 This affects the model performance especially for short wavelengths.

The outstanding question, then, is whether the FSC proxy model can be used for assessment of topographic site effects in ridges like the one described here. Considering previous results and discussion, we assume topographic effects should be visible on the main ridge A1 (where Stations 3 and 6 were located) up to about $3.5 \mathrm{~Hz}$ (see section Amplification of ground motion and potential dominant 545 direction). They should be dominant up to about $2 \mathrm{~Hz}$ on the horizontal component on ridge A1, assuming that $\mathrm{p}$-wave velocity $\mathrm{V}_{\mathrm{p}}$ is about $1.7 . \mathrm{V}_{\mathrm{s}}(\mathrm{Kim}$ et al., 2005), and above $2 \mathrm{~Hz}$ on the smaller ridge A2 (where Station 4 was located). For $V_{s}$ between $750 \mathrm{~m} \cdot \mathrm{s}^{-1}$ and $1500 \mathrm{~m} \cdot \mathrm{s}^{-1}$, and at low frequencies (below 2Hz), the FSC model agrees with this pattern. Therefore, it seems relevant to use such a model for first order prediction of the topographic site effects on ground motion in the studied setting. To also account for lithological effects in ground motion prediction, a model like that of Grelle et al., (2016) may 
offer opportunities. However, such a model would require knowledge of the nature and geometry of the principal geological features in the subsurface, which is not available for our site.

\section{General discussion and conclusions}

We have studied a representative mountain ridge in the eastern Central Range of Taiwan, located at $3 \mathrm{~km}$

555 from the Longitudinal Valley Fault, in an area prone to earthquake induced landsliding. Using one year of continuous seismic recordings, our results from both ambient-noise and moderate earthquake signals are consistent with previous studies (e.g., Chávez -Garcia et al., 1996). We identified site effects all along the ridge profile in the frequency range of 1 to $10 \mathrm{~Hz}$. At the ridge base, the resonance of the sedimentary filling of the Mataian valley implies amplification of the ground motion at $3 \mathrm{~Hz}$. There, around $6 \mathrm{~Hz}$, we

560 identify a directivity effect on earthquake signals that may be due to the possible generation of surface wave at the valley edge. On the ridge flanks, the HVSR and SSR show large peaks on the frequency range of $4-6 \mathrm{~Hz}$ depending on the locations, which may reflect the geological heterogeneities of the ridge. Amplification of the ground motion and directivity effects transverse to ridge elongation are observed at ridge crests, and are certainly due to the combined effects the topography and geology (cf.

565 Hailemikael et al., 2016; Assimaki and Mohammadi, 2018).

These complex seismic amplification effects, observed at ridge crest, ridge base and mid slope stations alike, at frequencies between 1 and $10 \mathrm{~Hz}$, are likely to trigger slope failure. This suggests that landslides may occur throughout the ridge topography, with size that might depend on the frequency content and level of shaking of the incoming wavefield. However, the landslide hazard may be higher at the ridge crests and base than on intermediate hillslopes. At ridge crests, polarization effects are conductive to slope failure, because they cause a maximum of ground motion amplification in the direction of maximum slope. At the ridge base, observations suggest that, in addition to the ground motion amplification, the potential for slope failure may be further increased by locally generated surface waves (cf. Jafarzadeh et al., 2015). The occurrence of these waves remains to be confirmed. 
575 We notice that indicators of ground motion such as PGV, PGA and Arias intensity are not adequate to describe the site effects and they should not be used to characterize these effects in global landslide models. Instead, new proxies that integrate the frequency dependence of the subsurface response in bedrock topography should be developed.

Our database does not allow evaluation of the possible impact at the ridge scale of a strong and directive

580 earthquake like the 1999 Chi-Chi earthquake. In such an event, the broadband sensors used in this study for the monitoring of strong ground motion, would be clipped, and accelerometers should be installed to properly record strong ground motion. Anticipation of topographic ridge response to a large earthquake remains an outstanding challenge due to possible soil non-linear effects (e.g., Bonilla et al., 2011).

Models based on topographic proxies hold promise for prediction and mapping of ground motion for

585 landslide hazard evaluation at the regional scale. The frequency dependent topographic prediction model of Maufroy et al., 2015 is not reproduce all important site effects observed in our study, because it does not deal with lithological effects. However, it seems suited to a general correction of the predicted ground motion for topographic site effects. A morpho-lithologic model such as that of Grelle et al., (2018) may provide better results for topographies covered by thick regolith.

590 To conclude, we recommend continuing to document the seismic response of ridges, increasing the number of seismic stations along hillslopes, where they lack in typical networks (Figure 1). Ambientnoise analysis should suffice to identify and map the variability of the site response. It is a fast method to acquire data especially in regions with low seismicity. Furthermore, we suggest installing accelerometers, during more than 1 year, to document ridge response to strong shaking. This is especially important in 595 areas where strong earthquakes can occur and induce a large number of landslides causing substantial human and economic losses.

\section{Data and Resources}


The list of earthquakes and their parameters were obtained from the Geophysical Database Management System, Central Weather Bureau (CWB, http://gdms.cwb.gov.tw), consulted in March 2018 and

600 November 2019. The geological layers of the studied site were found in MOEA, and Central Geological Survey, 2008, Geological Map Database (http://gis.moeacgs.gov.tw/gwh/gsb97-1/sys8/index.cfm) last accessed December 12, 2017. Landslide data were downloaded from https://www.sciencebase.gov/catalog/item/586d824ce4b0f5ce109fc9a6 consulted in August 2017. The recorded seismic data are available at https://geofon.gfz-potsdam.de/doi/network/5K/2015. ShakeMaps

605 archive are provided by U.S. Geological survey (https://earthquake.usgs.gov/data/shakemap/) consulted in 2017. (Data for Station EGFH were provided by the Central Weather Bureau. Signal analysis was pursued with the Obspy toolbox, Geospy (http://www.geopsy.org/) and the code of J. Burjánek et al., (2014) for TFPA. Noise windows where extracted with the code of Perron et al., (2018). Complementary information on site characteristics, signal processing and results is provided in the supplemental material 610 of this article.

\section{Acknowledgments}

The Ministry of Science and Technology (MOST) in Taiwan, under Grant MOST107-2636-M-009-004, through the Young Scholar Fellowship Einstein Program and the Academia Sinica (grant AS-TP-108M08) supported this work. The Taiwan Central Geological Survey (CGS), MOEA (Project Number:

615 B10635) also provided financial support. We thank the Taiwan Central Weather Bureau for providing data from its station EGFH. We are grateful to C. Baillard for help with signal processing, and to Y. Burjánek for sharing the TFPA code and providing relevant feedbacks. We thank K. Cook and J. Turowski for their contribution to field work and the reviewers for helping us to improve our manuscript. 
Alfaro, P., J. Delgado, F. J. García-Tortosa, J. J. Giner, L. Lenti, C. López-Casado, S. Martino, and G. Scarascia Mugnozza (2012). The role of near-field interaction between seismic waves and slope on the triggering of a rockslide at Lorca (SE Spain), Nat. Hazards Earth Syst. Sci. 12 3631-3643, doi: 10.5194/nhess-12-3631-2012.

625 Ashford, S. A., and N. Sitar (1997). Analysis of topographic amplification of inclined shear waves in a steep coastal bluff, Bull. Seismol. Soc. Am. 87, 692-700.

Ashford, S. A., N. Sitar, J. Lysmer, and N. Deng (1997). Topographic effects on the seismic response of steep slopes, Bull. Seismol. Soc. Am. 87 701-709.

Assimaki, D., G. Gazetas, and E. Kausel (2005). Effects of local soil conditions on the topographic 630 aggravation of seismic motion: Parametric investigation and recorded field evidence from the 1999 Athens earthquake, Bull. Seismol. Soc. Am. 95 1059-1089, doi: 10.1785/0120040055.

Assimaki, D., and S. Jeong (2013). Ground-motion observations at hotel Montana during the M 7.0 2010 Haiti earthquake: Topography or soil amplification?, Bull. Seismol. Soc. Am. 103 2577-2590, doi: $10.1785 / 0120120242$.

635 Assimaki, D., and K. Mohammadi (2018). On the complexity of seismic waves trapped in irregular topographies, Soil Dyn. Earthq. Eng. 114 424-437, doi: 10.1016/j.soildyn.2018.07.020.

Astier, J. L. (1971). Géophysique appliquée à l'hydrogéologie.

Baillard, C., W. C. Crawford, V. Ballu, C. Hibert, and A. Mangeney (2014). An automatic kurtosis-based P-and S-phase picker designed for local seismic networks, Bull. Seismol. Soc. Am. 104 394-409, doi:

$640 \quad 10.1785 / 0120120347$.

Bard, P.-Y. (1982). Diffracted waves and displacement field over two-dimensional elevated topographies, 
Geophys. J. Int., 71 731-760.

Bard, P.-Y. (1998). Microtremor measurement : a tool for site effect estimation?, in Proceeding of the Second International Symposium on the Effects of Surface Geology on Seismic Motion. Yokohama, Japan

645 T. Irikura, K., Kudo, K., Okada, H., and Sasatani (Editor), 1251-1279.

Bard, P.-Y., and SESAME-Team, (2004). Guidelines for the Implementation of the H / V Spectral Ratio Technique on Ambient Vibrations Measurements, Processing and Interpretation. SESAME European research project, WP12 - Deliverable D23.12. European Commission-EVG1-CT-2000-00026 SESAME

Bonilla, L. F. Y., K. Tsuda, N. Pulido, J. Regnier, and A. Laurendeau (2011). Nonlinear site response 650 evidence of K-NET and KiK-net records from the 2011 off the Pacific coast of Tohoku Earthquake, Earth, Planets Sp. 63 785-789, doi: 10.5047/eps.2011.06.012.

Bonnefoy-Claudet, S., F. Cotton, and P.-Y. Bard (2006). The nature of noise wavefield and its applications for site effects studies. A literature review, Earth-Science Rev., 79 205-227, doi: 10.1016/j.earscirev.2006.07.004.

655 Boore, D. M. (1973). The effect of simple topography on seismic waves: implications for the accelerations recorded at Pacoima Dam, San Fernando Valley, California, Bull. Seismol. Soc. Am. 63 $1603-1609$.

Borcherdt, R. D. (1970). Effects of Local Geology on Ground Motion Near San Francisco bay, Bull. Seismol. Soc. Am. 60 29-61.

660 Bouchon, M., C. A. Schultz, and M. N. Toksöz (1996). Effect of three-dimensional topography on seismic motion, J. Geophys. Res. Solid Earth 101 5835-5846.

Bourdeau, C., H.-B. Havenith, J.-A. Fleurisson, and G. Grandjean (2004). Numerical Modelling of Seismic Slope Stability, in Engineering geology for infrastructure planning in Europe, Springer, Berlin, 
Heidelberg. 671-684

665 Bozzano, F., E. Cardarelli, M. Cercato, L. Lenti, S. Martino, A. Paciello, and G. S. Mugnozza (2008). Engineering-geology model of the seismically-induced Cerda landslide (Sicily, Italy), Boll. di Geofis. Teor. ed Appl. 49 205-225.

Buech, F., T. R. Davies, and J. R. Pettinga (2010). The little red hill seismic experimental study: Topographic effects on ground motion at a bedrock-dominated mountain edifice, Bull. Seismol. Soc. Am. 100 2219-2229, doi: 10.1785/0120090345.

Burjánek, J., B. Edwards, and D. Fäh (2014). Empirical evidence of local seismic effects at sites with pronounced topography: A systematic approach, Geophys. J. Int. 197 608-619, doi: 10.1093/gji/ggu014

Burjánek, J., G. Gassner-stamm, V. Poggi, J. R. Moore, and D. Fah (2010). Ambient vibration analysis of an unstable mountain slope, Geophys. J. Int. 180 820-828, doi: 10.1111/j.1365-246X.2009.04451.x.

675 Cadet, H., P.-Y. Bard, and A. Rodriguez-Marek (2011). Site effect assessment using KiK-net data: Part 1. A simple correction procedure for surface/downhole spectral ratios, Bull. Earthq. Eng. 10 421-448, doi: 10.1007/s10518-011-9283-1.

Celebi, M. (1991). Topographical and geological amplification: case studies and engineering implications, Struct. Saf. 10 199-217.

680 Chávez-Garcia, F. J., L. R. Sánchez, and D. Hatzfeld (1996). Topographic site effects and HVSR. A comparison between observations and theory, Bull. Seismol. Soc. Am. 86 1559-1573.

Cheng, C. T., S. J. Chiou, C. T. Lee, and Y. Ben Tsai (2007). Study on probabilistic seismic hazard maps of taiwan after chi-chi earthquake, J. Geoengin. 2 19-28 doi: 10.6310/jog.2007.2(1).3. 
Chi, W. C., D. Dreger, and A. Kaverina (2001). Finite-source modeling of the 1999 Taiwan (Chi-Chi) 685 earthquake derived from a dense strong-motion network, Bull. Seismol. Soc. Am. 91 1144-1157, doi: $10.1785 / 0120000732$.

Cultrera, G., E. D'Alema, S. Amoroso, B. Angioni, P. Bordoni, L. Cantore, F. Cara, A. Caserta, R. Cogliano, M. D'Amico, et al. (2016). Site effect studies following the $2016 \mathrm{Mw} 6.0$ Amatrice earthquake (Italy): the Emersito Task Force activities, Ann. Geophys. 59 1-9, doi: 10.4401/ag-7189.

690 Davis, L. L., and L. R. West, 1973, Observed effects of topography on ground motion, Bull. Seismol. Soc. Am. 63 283-298.

Del Gaudio, V., S. Coccia, J. Wasowski, M. R. Gallipoli, and M. Mucciarelli (2008). Detection of directivity in seismic site response from microtremor spectral analysis, Nat. Hazards Earth Syst. Sci. 8 751-762, doi: 10.5194/nhess-8-751-2008.

Del Gaudio, V., Y. Luo, Y. Wang, and J. Wasowski (2018). Using ambient noise to characterise seismic slope response: The case of Qiaozhuang peri-urban hillslopes (Sichuan, China), Eng. Geol. 246 374-390, doi: 10.1016/j.enggeo.2018.10.008.

Del Gaudio, V., and J. Wasowski (2007). Directivity of slope dynamic response to seismic shaking, Geophys. Res. Lett. 34 1-8, doi: 10.1029/2007GL029842.

700 Formisano, L. A., M. La Rocca, E. Del Pezzo, D. Galluzzo, C. Fischione, and R. Scarpa (2012). Topography effects in the polarization of earthquake signals: A comparison between surface and deep recordings, Boll. di Geofis. Teor. ed Appl. 53 471-484, doi: 10.4430/bgta0055.

Gallen, S. F., M. K. Clark, and J. W. Godt (2015). Coseismic landslides reveal near-surface rock strength in a highrelief, tectonically active setting, Geology 43 11-14, doi: 10.1130/G36080.1.

705 Geli, L., P.-Y. Bard, and B. Jullien (1988). The effect of topography on earthquake ground motion: a review and new results, Bull. Seismol. Soc. Am. 78 42-63. 
Glinsky, N., and E. Bertrand (2017). Numerical investigation of topographical site effects: parametric study on simplified geometries and impact of the inner geological structure, in Proceedings of 16WCEE, 16th World Conference on Earthquake Engineering.

710 Grelle, G., L. Bonito, P. Revellino, and G. Sappa (2016). Frequency-dependent topographic seismic amplification by a "gray box model" using GIS morphometric data, Rend. Online Soc. Geol. Ital., 41 342-345, doi: 10.3301/ROL.2016.163.

Grelle, G., C. Wood, L. Bonito, G. Sappa, P. Revellino, S. Rahimi, and F. M. Guadagno (2018). A reliable computerized litho-morphometric model for development of 3D maps of Topographic 715 Aggravation Factor (TAF): the cases of East Mountain (Utah, USA) and Port au Prince (Haiti), Bull. Earthq. Eng. 16 1725-1750, doi: 10.1007/s10518-017-0272-x.

Hailemikael, S., L. Lenti, S. Martino, A. Paciello, D. Rossi, and G. Scarascia Mugnozza (2016). Groundmotion amplification at the Colle di Roio ridge, central Italy: A combined effect of stratigraphy and topography, Geophys. J. Int. 206 1-18, doi: 10.1093/gji/ggw120.

720 Hallier, S., E. Chaljub, M. Bouchon, and H. Sekiguchi (2008). Revisiting the basin-edge effect at Kobe during the 1995 Hyogo-Ken Nanbu earthquake, Pure Appl. Geophys. 165 1751-1760, doi: 10.1007/s00024-008-0404-y.

Harp, E. L., and R. C. Wilson (1995). Shaking intensity thresholds for rock falls and slides: evidence from 1987 Whittier Narrows and Superstition Hills earthquake strong- motion records, Bull. Seismol. Soc. 725 Am. 86 1739-1757.

Hartzell, S., A. L. Leeds, and R. W. Jibson (2017). Seismic response of soft deposits due to landslide: The mission peak, California, landslide, Bull. Seismol. Soc. Am. 107 2008-2020, doi: 10.1785/0120170033.

Hartzell, S., M. Meremonte, L. Ramirez-Guzmán, and D. McNamara (2014). Ground motion in the presence of complex topography: Earthquake and ambient noise sources, Bull. Seismol. Soc. Am. 104 32 
Hill, D. P., P. A. Reasenberg, A. Michael, W.J. Arabaz, G. Beroza, D. Brumbaugh, J.N. Brune, R. Castro, S. Davis, D. DePolo, et al. (1993). Seismicity remotely triggered by the magnitude 7.3 landers, California, earthquake, Science 260 1617-1623, doi: 10.1126/science.260.5114.1617.

Hollender, F., Z. Roumelioti, J. Regnier, V. Perron, and P.-Y. Bard (2018). Respective Advantages of

735 Surface and Downhole Reference Stations for Site Effect Studies : Lessons Learnt From the Argonet (Cephalonia Island, Greece ) and Cadarache (Provence, France ) Vertical Arrays, in 16th european conference on earthquake engineering, 1-12.

Hough, S. E., J. R. Altidor, D. Anglade, D. Given, M. G. Janvier, J. Z. Maharrey, M. Meremonte, B. S. L. Mildor, C. Prepetit, and A. Yong (2010). Localized damage caused by topographic amplification during 740 the 2010 M7.0 Haiti earthquake, Nat. Geosci. 3 778-782, doi: 10.1038/ngeo988.

Huang, J. C., J. D. Milliman, T. Y. Lee, Y. C. Chen, J. F. Lee, C. C. Liu, J. C. Lin, and S. J. Kao (2017). Terrain attributes of earthquake- and rainstorm-induced landslides in orogenic mountain Belt, Taiwan, Earth Surface Processes and Landforms 42 1549-1559, doi: 10.1002/esp.4112.

Hung, C., G. W. Lin, H. S. Syu, C. W. Chen, and H. Y. Yen (2018). Analysis of the Aso-Bridge landslide 745 during the 2016 Kumamoto earthquakes in Japan, Bull. Eng. Geol. Environ. 77 1439-1449, doi: 10.1007/s10064-017-1103-7.

Jafarzadeh, F., M. M. Shahrabi, and H. F. Jahromi (2015). On the role of topographic amplification in seismic slope instabilities, J. Rock Mech. Geotech. Eng. 7 163-170, doi: 10.1016/j.jrmge.2015.02.009.

Jeong, S., D. Asimaki, J. Dafni, and J. Wartman (2019). How topography-dependent are topographic

750 effects? Complementary numerical modeling of centrifuge experiments, Soil Dyn. Earthq. Eng. 116654 667, doi: 10.1016/j.soildyn.2018.10.028.

Jibson, R. W., E. L. Harp, and J. A. Michael (2000). A method for producing digital probabilistic seismic 65 33 
landslide hazard maps, Eng. Geol. 58 271-289, doi: 10.1016/S0013-7952(00)00039-9.

Jibson, R. W., E. L. Harp, W. Schulz, and D. K. Keefer (2004). Landslides triggered by the 2002 Denali

755 fault, Alaska, earthquake and the inferred nature of the strong shaking, Earthq. Spectra 20 669-691, doi: 10.1193/1.1778173.

Kaiser, A., C. Holden, and C. Massey (2013). Determination of site amplification, polarization and topographic effects in the seismic response of the Port Hills following the 2011 Christchurch earthquake, in NZSEE Conference Wellington, New Zealand, 1-8.

760 Kawase, H., and K. Aki (1990). Topography effect at the critical SV-wave incidence Possible explanation of damage pattern by the Whittier Narrows, California, earthquake of 1 October 1987, Bull. Seismol. Soc. Am. 80 1-22.

Kennett, B. L. N., and E. R. Engdahl (1991). Travel times for global earthquake location and phase association, Geophys. J. Int. 105 429-465.

765 Kim, K. H., J. M. Chiu, J. Pujol, K. C. Chen, B. S. Huang, Y. H. Yeh, and P. Shen (2005). Threedimensional VP and VS structural models associated with the active subduction and collision tectonics in the Taiwan region, Geophys. J. Int. 162 204-220, doi: 10.1111/j.1365-246X.2005.02657.x.

Konno, K., and T. Ohmachi (1998). Ground-motion characteristics estimated from spectral ratio between horizontal and vertical components of microtremor, Bull. Seismol. Soc. Am. 88 228-241.

770 Kramer, S. L. (1996). Geotechnical earthquakes engineering, 376.

Kuo, C. H., K. L. Wen, C. M. Lin, N. C. Hsiao, and D. Y. Chen (2018). Site amplifications and the effect on local magnitude determination at stations of the surface-downhole network in Taiwan, Soil Dyn. Earthq. Eng. 104 106-116, doi: 10.1016/j.soildyn.2017.10.003.

Lee, C. T., C. C. Huang, J. F. Lee, K. L. Pan, M. L. Lin, and J. J. Dong (2008). Statistical approach to 34 
775 earthquake-induced landslide susceptibility, Eng. Geol. 100 43-58, doi: 10.1016/j.enggeo.2008.03.004.

Liao, H., and C. T. Lee (2000). Landsides triggered by the Chi-Chi Earthquake, in Proceedings of the 21st Asian Conference on Remote Sensing, 383-388.

Lin, C., Y. Yeh, H. Yen, K. Chen, B. Huang, S. W. Roecker, and J. Chiu (1998). Three-dimensional elastic wave velocity structure of the Hualien region of Taiwan- Evidence of active crustal exhumation, 780 Tectonics 17 89-103.

Marc, O., N. Hovius, P. Meunier, T. Gorum, and T. Uchida (2016). A seismologically consistent expression for the total area and volume of earthquake-triggered landsliding., J. Geophys. Res. Earth Surf. 121 640-663, doi: 10.1002/2015JF003732.

Massa, M., S. Barani, and S. Lovati (2014). Overview of topographic effects based on experimental 785 observations: Meaning, causes and possible interpretations, Geophys. J. Int. 197 1537-1550, doi: 10.1093/gji/ggt341.

Massa, M., S. Lovati, E. D’Alema, G. Ferretti, and M. Bakavoli (2010). An experimental approach for estimating seismic amplification effects at the top of a ridge, and the implication for ground-motion predictions: The case of Narni, Central Italy, Bull. Seismol. Soc. Am. 100 3020-3034, doi: 10.1785/0120090382.

Massey, C., F. Della Pasqua, C. Holden, A. Kaiser, L. Richards, J. Wartman, M. J. McSaveney, G. Archibald, M. Yetton, and L. Janku (2017). Rock slope response to strong earthquake shaking, Landslides 14 249-268, doi: 10.1007/s10346-016-0684-8.

Massey, C., D. Townsend, E. Rathje, K. E. Allstadt, B. Lukovic, Y. Kaneko, B. Bradley, J. Wartman, 795 R.W. Jibson, D. N. Petley, et al., 2018, Landslides triggered by the 14 November 2016 Mw 7.8 Kaikōura earthquake, New Zealand, Bull. Seismol. Soc. Am. 108 1630-1648 doi: 10.1785/0120170305.

Maufroy, E., V. M. Cruz-Atienza, F. Cotton, and S. Gaffet, 2015, Frequency-Scaled Curvature as a Proxy 35 
for Topographic Site-Effect Amplification and Ground-Motion Variability, Bull. Seismol. Soc. Am. 105 $354-367$.

800 Maufroy, E., E. Chaljub, F. Hollender, P.-Y. Bard, J. Kristek, P. Moczo, F. De Martin, N. Theodoulidis, M. Manakou, C. Guyonnet-Benaize, et al., 2016, 3D numerical simulation and ground motion prediction: Verification, validation and beyond - Lessons from the E2VP project, Soil Dyn. Earthq. Eng. 91 53-71, doi: 10.1016/j.soildyn.2016.09.047.

Maufroy, E., P. Lacroix, E. Chaljub, C. Sira, G. Grelle,, L. Bonito, M. Causse, V.M. Cruz-Atienza, F.

805 Hollender, F. Cotton, et al., (2018). Towards rapid prediction of topographic amplification at small scales : contribution of the FSC proxy and pleiades terrain models for the 2016 Amatrice earthquake (Italy, MW 6.0), in Proceedings of the 16th European Conference on Earthquake Engineering.

Meunier, P., N. Hovius, and J. A. Haines (2008). Topographic site effects and the location of earthquake induced landslides, Earth Planet. Sci. Lett. 275 221-232, doi: 10.1016/j.eps1.2008.07.020.

810 Moore, J. R., V. Gischig, F. Amann, M. Hunziker, and J. Burjánek (2012). Earthquake-triggered rock slope failures: Damage and site effects, in Proceedings 11th International \& 2nd North American Symposium on Landslides 869-875.

Nakamura, Y. (1989). A Method for Dynamic Characteristics Estimation of Subsurface using Microtremor on The Ground Surface, Q. Rep. Railw. Tech. Res. Inst. 30, 25-33, doi: 10.1149/1.2069306.

815 Nguyen, K. V., and B. Gatmiri (2007). Evaluation of seismic ground motion induced by topographic irregularity, Soil Dyn. Earthq. Eng. 27 183-188, doi: 10.1016/j.soildyn.2006.06.005.

Olsson, U. (2005). Confidence intervals for the mean of a log-normal distribution, J. Stat. Educ. 13 doi: DOI: $10.1080 / 10691898.2005$.

Panzera, F., S. D’Amico, A. Lotteri, P. Galea, and G. Lombardo (2012). Seismic site response of unstable 820 steep slope using noise measurements: The case study of Xemxija Bay area, Malta, Nat. Hazards Earth 
Syst. Sci. 12 3421-3431, doi: 10.5194/nhess-12-3421-2012.

Paolucci, R. (2002). Amplification of earthquake ground motion by steep topographic irregularities, Earthq. Eng. Struct. Dyn. 31 1831-1853.

Pedersen, H. A., B. Le Brun, D. Hatzfeld, M. Campillo, and P.-Y. Bard (1994). Ground motion amplitude 825 across ridges, Bull. Seismol. Soc. Am. 84 1786-1800.

Pelekis, P., A. Batilas, E. Pefani, V. Vlachakis, and G. Athanasopoulos (2017). Surface topography and site stratigraphy effects on the seismic response of a slope in the Achaia-Ilia (Greece) 2008 Mw6.4 earthquake, Soil Dyn. Earthq. Eng. 100 538-554, doi: 10.1016/j.soildyn.2017.05.038.

Perron, V., A. Laurendeau, F. Hollender, P. Y. Bard, C. Gelis, P. Traversa, and S. Drouet (2018).

830 Selecting time windows of seismic phases and noise for engineering seismology applications: a versatile methodology and algorithm, Bull. Earthq. Eng. 16 2211-2225, doi: 10.1007/s10518-017-0131-9.

Perron, V. (2017). Apport des enregistrements de séismes et de bruit de fond pour l'évaluation sitespécifique de l'aléa sismique en zone de sismicité faible à modérée, Université Grenoble Alpes.

Pilz, M., S. Parolai, B. Petrovic, N. Silacheva, T. Abakanov, S. Orunbaev, and B. Moldobekov (2018).

835 Basin-edge generated Rayleigh waves in the almaty basin and corresponding consequences for ground motion amplification, Geophys. J. Int. 213 301-316, doi: 10.1093/gji/ggx555.

Pischiutta, M., P. Cianfarra, F. Salvini, F. Cara, and P. Vannoli (2018). A systematic analysis of directional site effects at stations of the Italian seismic network to test the role of local topography, Geophys. J. Int. 214 635-650, doi: 10.1093/gji/ggy133.

840 Pischiutta, M., and A. Rovelli (2014). Ground motion amplification at sites with pronounced topography: the controversial role of local geology, Gngts 253-260.

Ponti, D. J., and R. E. Wells (1991). Off-fault ground ruptures in the Santa Cruz Mountains, California: 37 
Ridge-top spreading versus tectonic extension during the 1989 Loma Prieta earthquakes, Bull. Seism. Soc. Am., 81 1480-1510.

845 Rai, M., A. Rodriguez-Marek, and A. Yong (2016). An Empirical Model to Predict Topographic Effects in Strong Ground Motion Using California Small-to Medium-Magnitude Earthquake Database, Earthq. Spectra 32 1033-1054.

Roy, R., D. Ghosh, , and G. Bhattacharya, (2015). Influence of strong motion characteristics on permanent displacement of slopes, Landslides 13 279-292.

850 Sánchez-Sesma, F. J., and M. Campillo (1993). Topographic effects for incident P, SV and Rayleigh waves, Tectonophysics 218 113-125, doi: 10.1016/0040-1951(93)90263-J.

Semblat, J.-F., R. Paolucci, and A.-M. Duval (2003). Simplified vibratory characterization of alluvial basins, Comptes Rendus Geosciences 335 365-370, doi: 10.1016/S1631-0713(03)00058-0.

Sepulveda, S. A., W. Murphy, and D. N. Petley (2005). Topographic controls on coseismic rock slides 855 during the 1999 Chi-Chi earthquake, Taiwan, Q. J. Eng. Geol. Hydrogeol. 38 189-196, doi: $10.1144 / 1470-9236 / 04-062$.

Shearer, P., and J. Orcutt (1987). Surface and near-surface effects on seismic waves — theory and borehole seismometer results, Bull. Seismol. Soc. 77 1168-1196.

Specht, S. Von, U. Ozturk, G. Veh, F. Cotton, and O. Korup (2019). Effects of finite source rupture on 860 landslide triggering : the $2016 \mathrm{M} \mathrm{w} 7$. 1 Kumamoto earthquake, Solid Earth 10 463-486, doi: https://doi.org/10.5194/se-10-463-2019.

Spudich, P., and L. N. Frazer (1984). Variable Rupture Velocity and Stress Drop, Bull. Seismol. Soc. Am. $742061-2082$.

Spudich, P., M. Hellweg, and W. H. K. Lee (1996). Directional topographic site response at Tarzana 
865 observed in aftershocks of the 1994 Northridge, California, earthquake: implications for mainshock motions, Bull. Seismol. Soc. Am. 86 193-208.

Steidl, J. H., A. G. Tumarkin, and R. J. Archuleta (1996). What is a reference site?, Bull. Seismol. Soc. Am. 86 1733-1748.

Stolte, A. C., B. R. Cox, and R. C. Lee (2017). An experimental topographic amplification study at Los 870 Alamos national laboratory using ambient vibrations, Bull. Seismol. Soc. Am. 107 1386-1401, doi: $10.1785 / 0120160269$.

Tibaldi, A., L. Ferrari, and G. Pasquarè (1995). Landslides triggered by earthquakes and their relations with faults and mountain slope geometry: an example from Ecuador, Geomorphology 11 215-226, doi: 10.1016/0169-555X(94)00060-5.

875 Trifunac, M. D., and A. G. Brady (1975). A study on the duration of strong earthquake ground motion, Bull. Seismol. Soc. Am. 65 581-626.

Wang, Y.-J., C.-H. Chan, Y. ing Lee, K. F. Ma, J. B. H. Shyu, R.-J. Rau, and C.-T. Cheng (2016). Probabilistic Seismic Hazard Assessment for Taiwan, Terr. Atmos. Ocean. Sci. 27 325-340, doi: 10.3319/TAO.2016.05.03.01(TEM)1.

880 Wartman, J., R. B. Seed, and J. D. Bray (2005). Shaking Table Modeling of Seismically Induced Deformations in Slopes, J. Geotech. Geoenvironmental Eng. 131 610-622, doi: 10.1061/(ASCE)10900241(2005)131:5(610).

Wilson, R. C., and D. K. Keefer (1985). Predicting aeral limits of earthquake-induced landsliding. Evaluating earthquake hazard in the Los Angeles Region., US Geological Survey Professional Paper $885 \quad 160072$. 


\section{Full mailing address}

Claire Rault, Laboratoire de Géologie de l'ENS 75005 Paris, now at BGRM, 45060 Orléans, France claire.rault@,brgm.fr, clairerault@gmail.com

890 Vvn Wei-An Chao, Department of Civil Engineering, National Chiao Tung University, Hsinchu 30010, Taiwanvvnchao@gmail.com

Céline Gelis, Institut de Radioprotection et de Sûreté Nucléaire (IRSN), 92260 Fontenay aux Roses, France, celine.gelis@irsn.fr

Arnaud Burtin, Institut de Physique du Globe de Paris, 75005 Paris, France, burtin@ipgp.fr

895 Jui-Ming Chang, Department of Geosciences, National Taiwan University, Taipei 10617, Taiwan, geomingical@gmail.com

Odin Marc, ETH Zurich, Sonneggstrasse, 5. 8092 Zürich. Switzerland, CNRS GET OMP, Av. Edouard Belin, 31400, Toulouse. odin.marc@erdw.ethz.ch

Yih-Min $\mathrm{Wu}$, Department of Geosciences, National Taiwan University, Taipei 10617, Taiwan 900 drymwu@ntu.edu.tw

Tz-Shin Lai, Seismological Center, Central Weather Bureau (CWB), Taipei 10048, Taiwan, heidi@scman.cwb.gov.tw

Niels Hovius Helmholtz Centre Potsdam, German Research Center for Geosciences (GFZ), Telegrafenberg, 14473 Potsdam, Germany, hovius@gfz-potsdam.de

905 Patrick Meunier, Laboratoire de géologie de l’ENS, 75005 Paris, France, meunier@geologie.ens.fr 


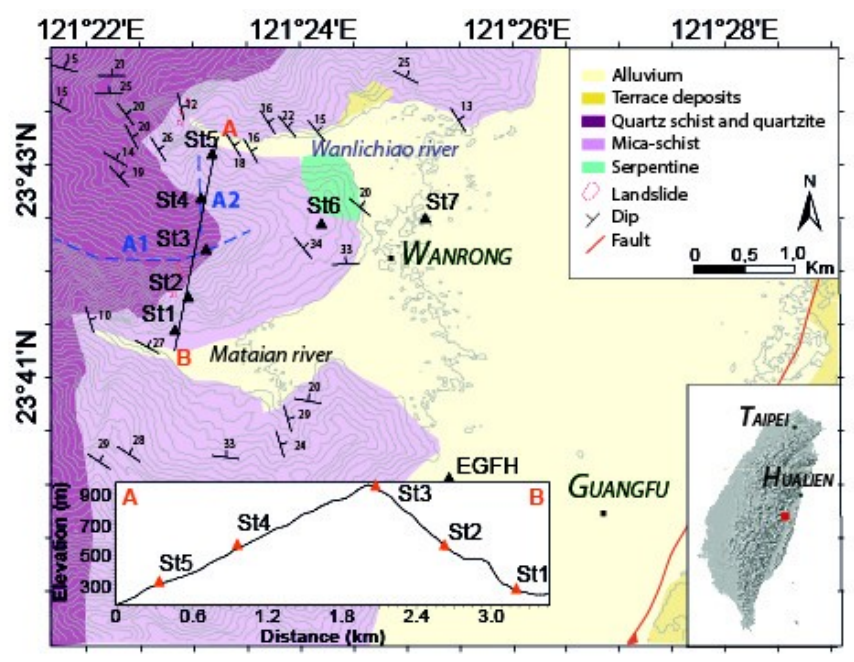

Figure 1: Experimental site setting. 7 broadband seismometers were installed in Wanrong, six on a ridge (stations 1 to 6 - Trillium compact 120s) and one in the sedimentary valley (station 7 - Guralp CMG-6TD). EGFH is a station of the Central Weather Bureau installed in a borehole at $163 \mathrm{~m}$ depth. The station 3 is installed along the main axis of the ridge $A 1$ and the station 4 is installed on the crest of the $2^{\text {nd }}$ order ridge $\mathrm{A} 2$. The hill is mainly made of schist dipping $20^{\circ}$ northeast.

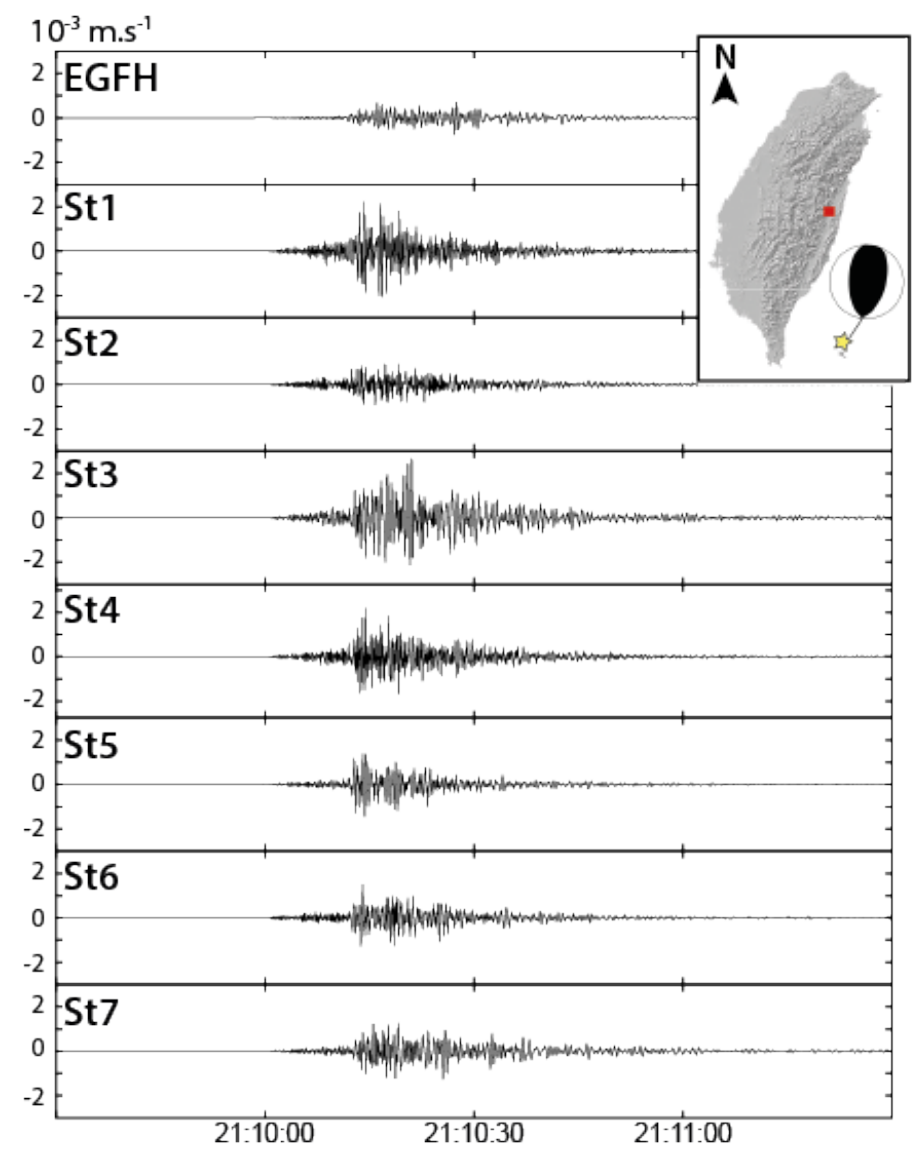


Figure 2: Velocities recorded by the network the $1^{\text {st }}$ of November 2015 during an earthquake with the

following characteristics magnitude: Ml: 5.9 - Mw 5.5, distance from station 3: $112 \mathrm{~km}$, depth: $18.8 \mathrm{~km}$, CWB earthquake $n^{\circ}:$ 104080). Signals are filtered between 1 and $6.5 \mathrm{~Hz}$.

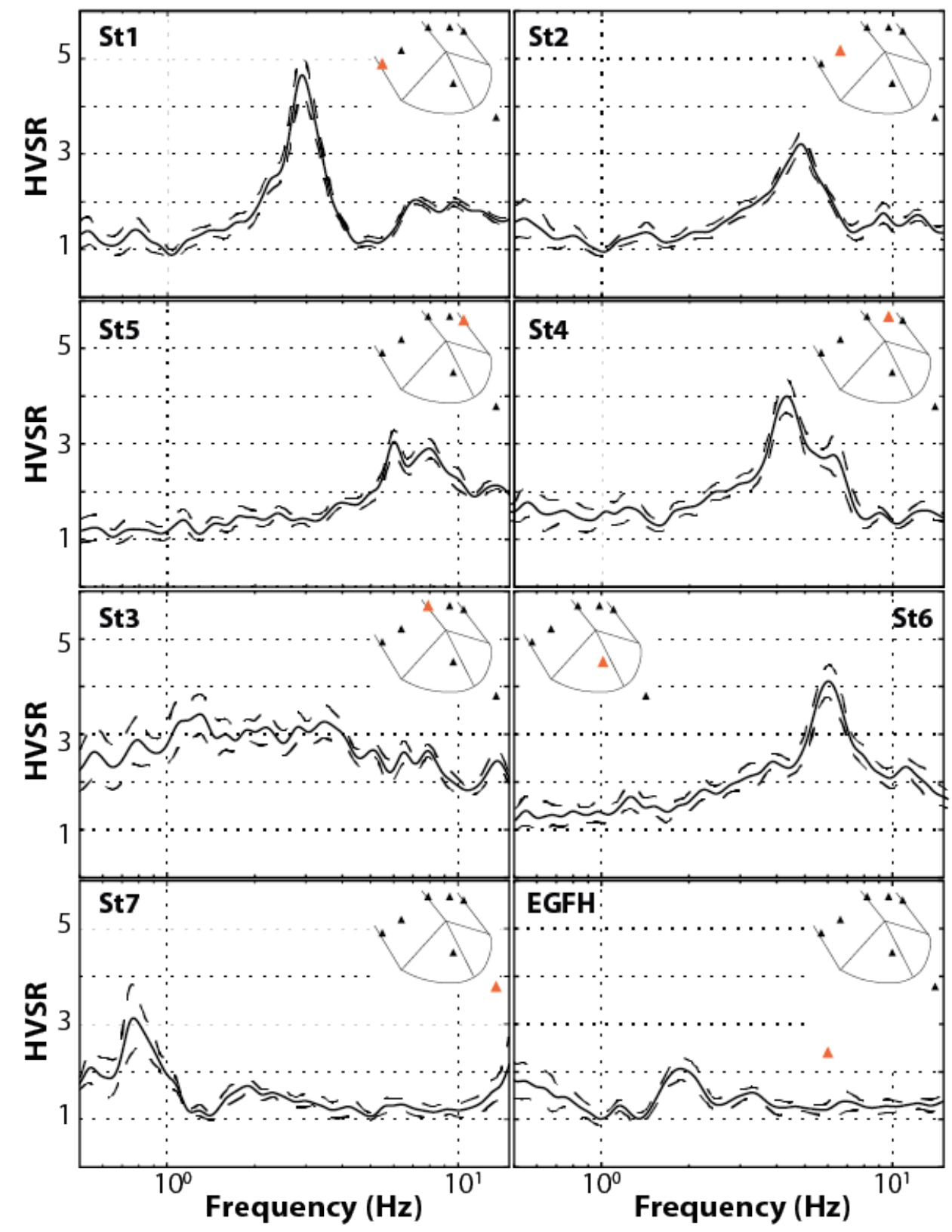

Figure 3: Mean (solid lines) and +/- standard deviation (dotted lines) of HVSR between $0.8 \mathrm{~Hz}$ to $15 \mathrm{~Hz}$ at the 8 stations. All the sites exhibit their own site-specific response. Stations 1 and 7 show clear peak at $9203 \mathrm{~Hz}$ and $0.7 \mathrm{~Hz}$ respectively that is characteristic of a $1 \mathrm{D}$ resonance frequency. Station EGFH as an almost flat response. 


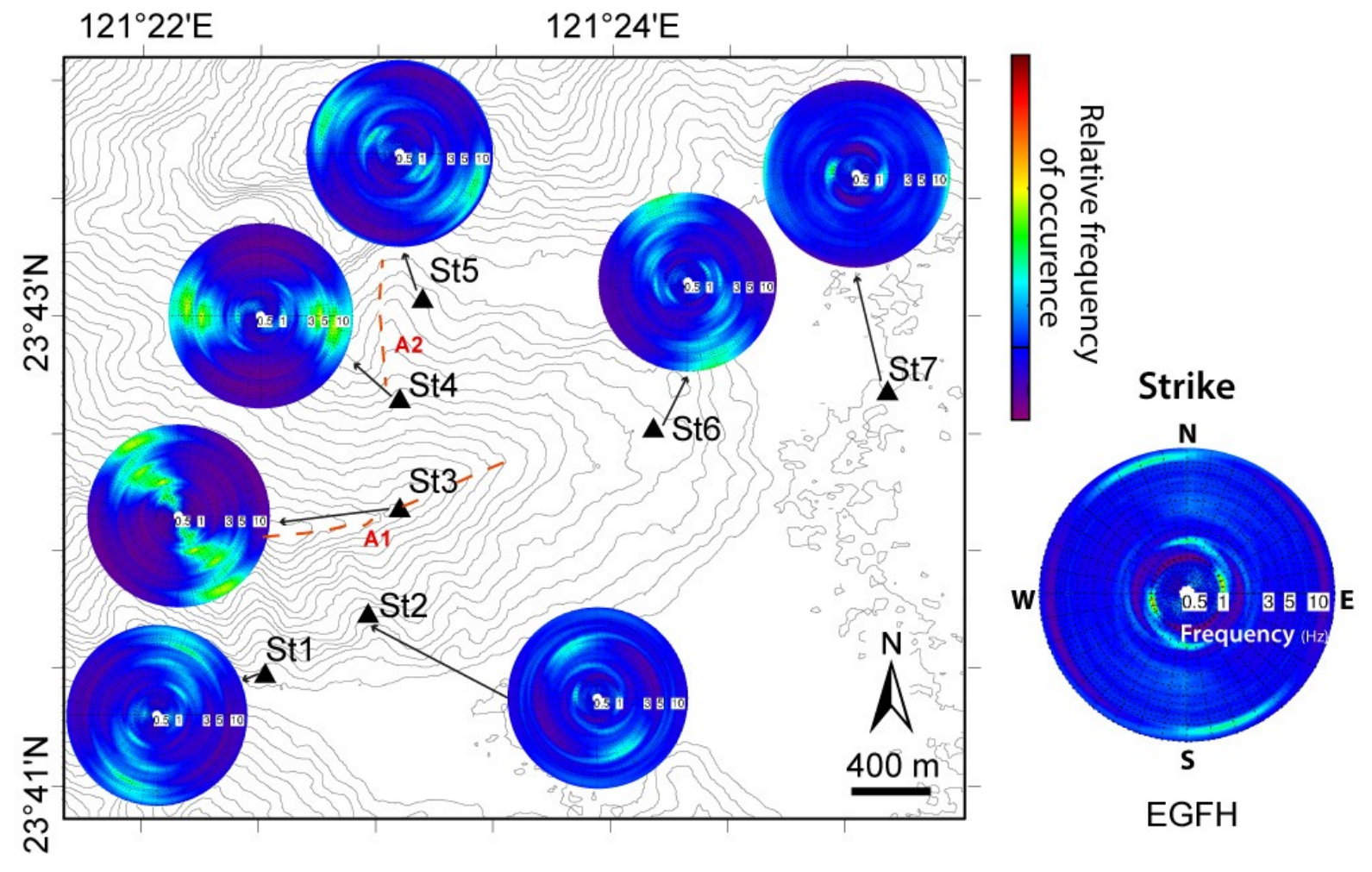

Figure 4: Strike distribution obtained from the TFPA (Burjanek et al 2010). Stations 3 and 4 show strong directional effects in the direction transverse of the ridge where they are installed. Plots are colored in red when the relative frequency of occurrence is high and blue when it is low.
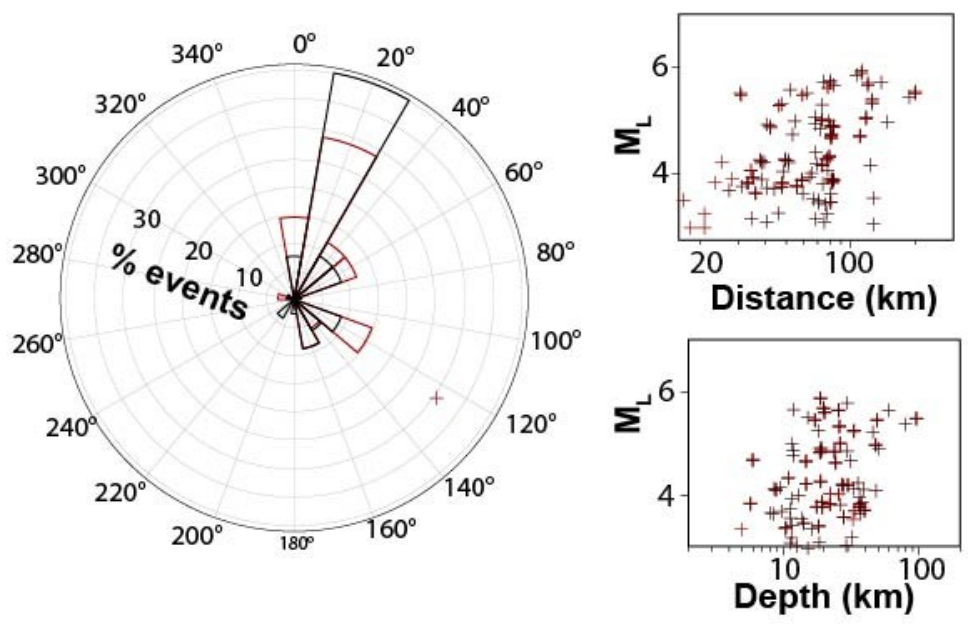

Figure 5: Characteristics of the selected earthquakes for this study that are common to all the 6 ridge stations and the station EGFH (41 EQs - SNR $>3$ ) and the ones that are common only to stations 3 and EGFH (79 EQs - SNR $>3$ and dist $>30 \mathrm{~km}$ ). a. Azimuth distribution of the recorded earthquakes. b. Local 
magnitude $\left(\mathrm{M}_{\mathrm{L}}\right)$ as a function of the hypocentral distance between the epicenter and the station St3. c. $M_{L}$ as a function of the depth of the source.

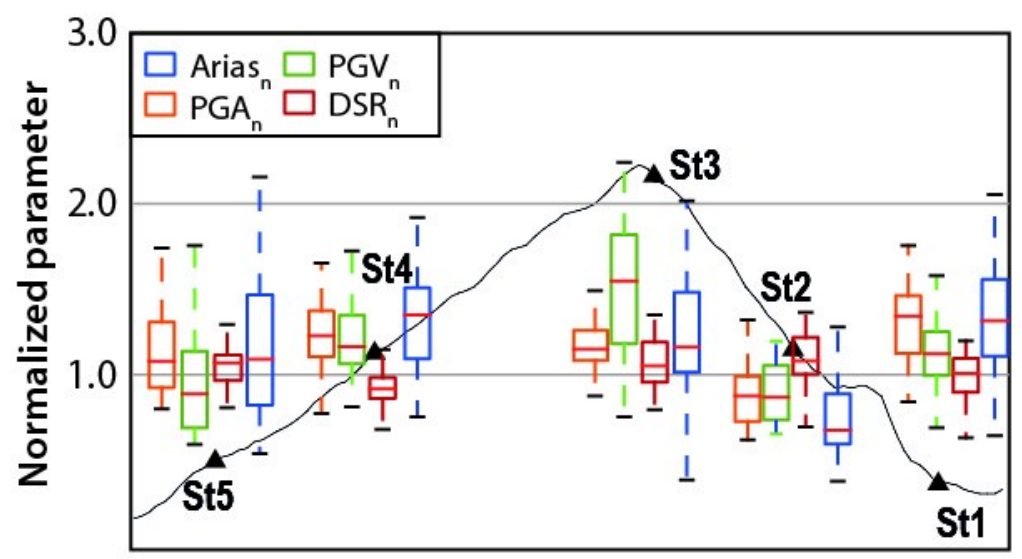

Figure 6: Box plots of the normalized Arias intensity, PGA, PGV and significant relative duration (DSR) for 41 earthquakes selected ( $S N R>3$ ) at stations 1 to 5 measured in the site-specific direction (i.e. direction of maximum amplitude). For each event, the recorded parameter at station $j$ is normalized by the average of the values measure at all the stations. The red line inside the boxes represents the average of normalized parameters. The external boundary of the boxes are respectively the first and the third quartile of their distribution. The vertical lines (whiskers) extend to the most extreme non-outlier data points.
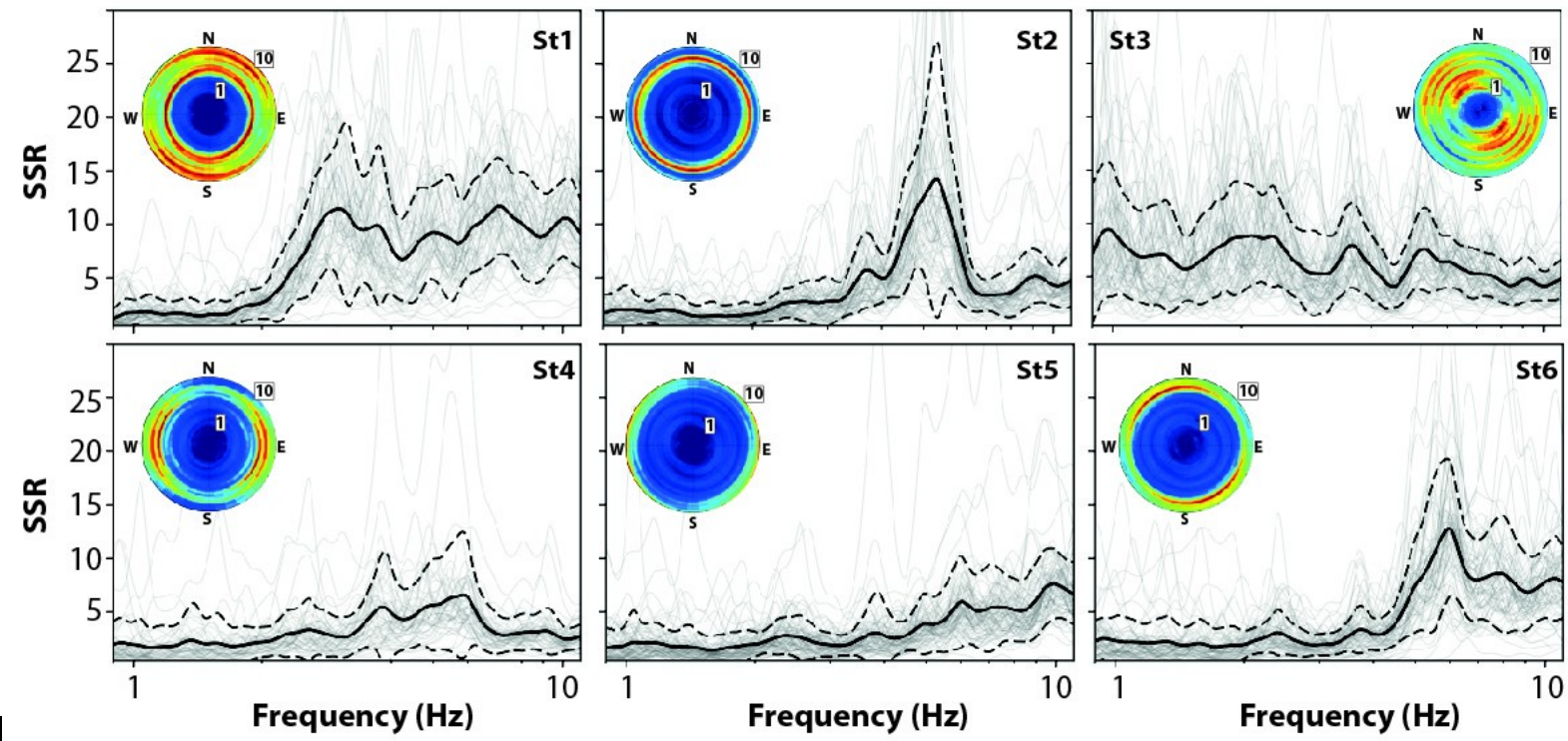

Figure 7: Mean and +/- standard deviation of SSR of the $\mathrm{N}$ component of the selected events (Number of selected EQs (SNR>3, dist>30km): St1:65; St2:78; St3: 79; St4: 48; St5: 80; St6:70). Polar plots represent the mean of the rotated horizontal SSR with frequency in radial axis. St1, St3, St4 and St6 show 
directional effects. Polar plots are colored from dark blue (lower value of SSR observed) to red (higher value of SSR observed).
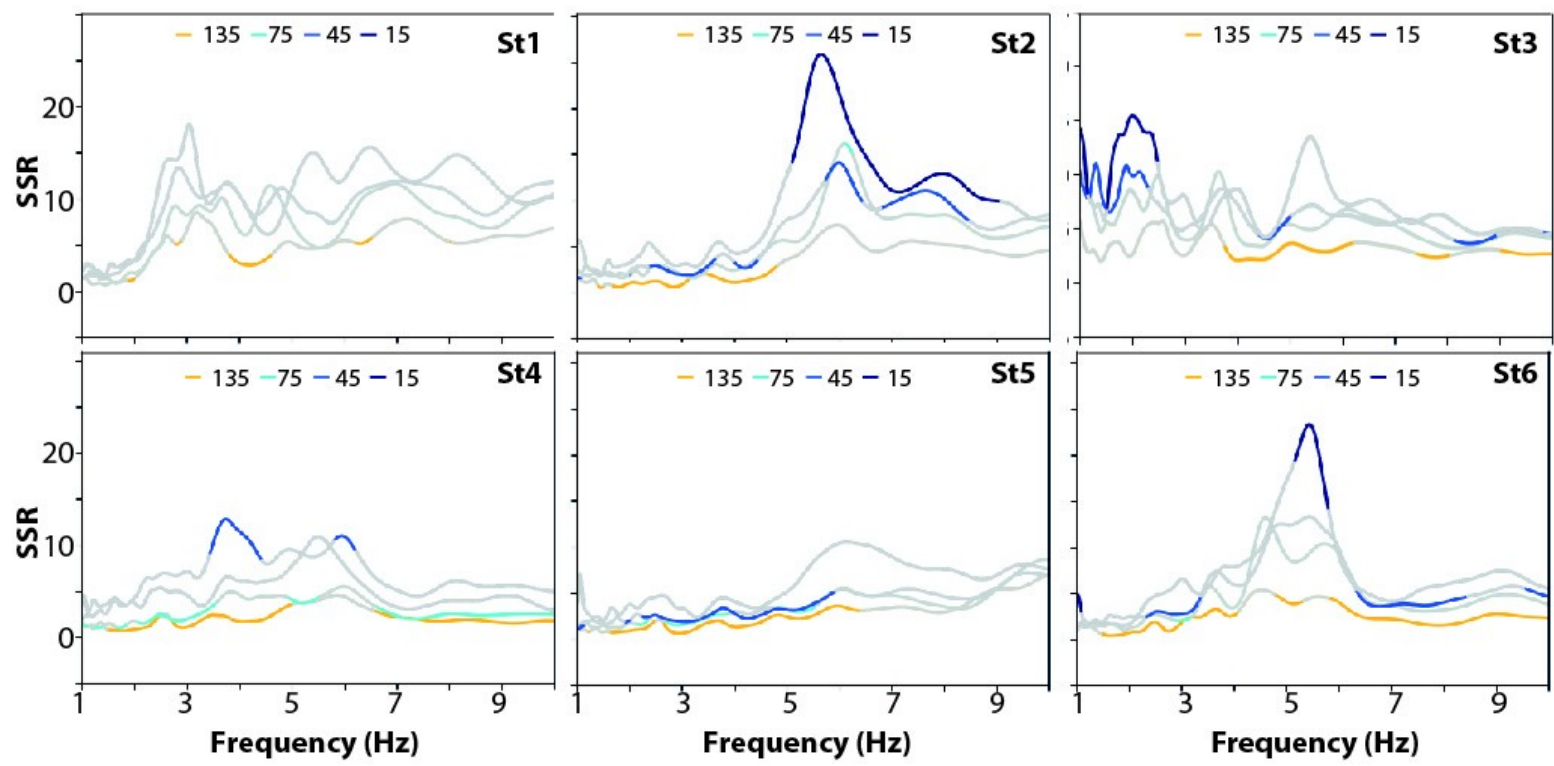

Figure 8: Mean SSR of subsets of events gathered according to their azimuth in intervals of 30 degrees.

The central azimuth angle characterizes the subsets. The curves are in grey when the values belong to the $95 \%$ interval of confidence (i.e. they are normally distributed) and coloured when they are out of it (i.e. the values are due to a statistical bias). Only subsets with more than 5 events are considered.
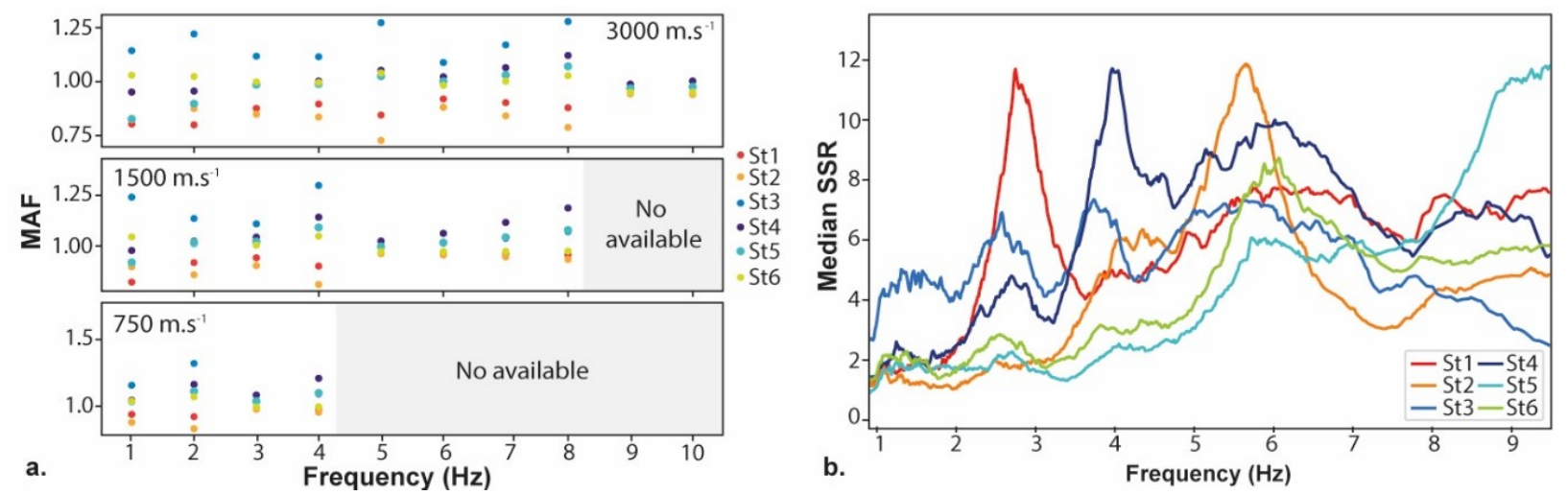

Figure 9: Median amplification factor estimated using (a.) frequency scale curvature proxy assuming a $V s=3000 \mathrm{~m} \cdot \mathrm{s}^{-1}$ and (b.) horizontal SSR (average of North and East SSR) relative to station EGFH. Note that the levels of amplification obtained with the two methods are not comparable. For Vs $=750 \mathrm{~m} \cdot \mathrm{s}^{-1}$ and $\mathrm{Vs}=1500 \mathrm{~m} \cdot \mathrm{s}^{-1}$ the FSC cannot be calculated for frequency higher than $4 \mathrm{~Hz}$ and $8 \mathrm{~Hz}$ because of the DEM resolution $(30 \mathrm{~m})$. 


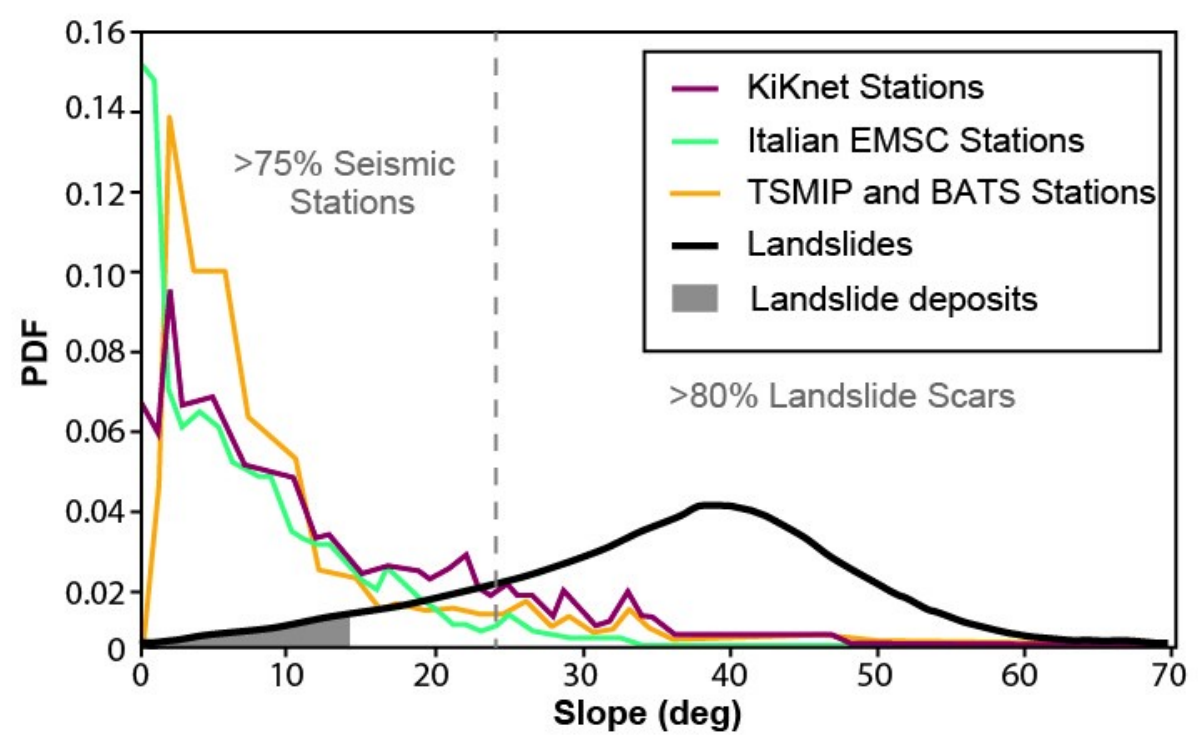

960 Figure 10: Distributions of slopes of seismic stations of Japanese, Italian and Taiwanese networks in comparison to the one of the slopes of landslides induced by the Mw 9.0 2011 Tohoku earthquake, the Mw 6.8 2004 Niigata-Chuetsu earthquake and the Mw 6.9 2008 Iwate earthquakes. The slopes are extracted from ALOS World 3D (AW3D) provided by JAXA. Table S1 (available in the supplementary material) gives the list of references for the landslide databases. There is clearly almost no seismic data records on range of slopes where earthquake-induced landslides occurred. 